\title{
The irregular chiasm C-roughest locus of Drosophila, which affects axonal projections and programmed cell death, encodes a novel immunoglobulin-like protein
}

\author{
Ricardo G.P. Ramos, ${ }^{1}$ Gabor L. Igloi, Beate Lichte, Ute Baumann, ${ }^{2}$ Dieter Maier, ${ }^{3}$ Thilo Schneider, \\ J. Helmut Brandstätter, ${ }^{4}$ Amalie Fröhlich, ${ }^{5}$ and Karl-Friedrich Fischbach ${ }^{6}$ \\ Institut für Biologie III, Albert-Ludwigs Universität, D-79104 Freiburg im Breisgau, Germany; ${ }^{3}$ Biozentrum Basel, \\ $\mathrm{CH}-4056$ Basel, Switzerland
}

\begin{abstract}
The axonal projection mutations irregular chiasm $C$ of Drosophila melanogaster comap and genetically interact with the roughest locus, which is required for programmed cell death in the developing retina. We cloned the genomic region in $3 \mathrm{C} 5$ by transposon tagging and identified a single transcription unit that produces a major, spatially and temporally regulated mRNA species of $\sim 5.0 \mathrm{~kb}$. Postembryonic expression is strong in the developing optic lobe and in the eye imaginal disc. The gene encodes a transmembrane protein of $\mathbf{7 6 4}$ amino acids with five extracellular immunoglobulin-like domains and similarity to the chicken axonal surface glycoprotein DM-GRASP/SC1/BEN. Both known irreC alleles reduce the level of transcription, whereas the roughest ${ }^{C T}$ mutation disrupts the intracellular domain of the protein.
\end{abstract}

[Key Words: Cell adhesion; Immunoglobulin superfamily; DM-GRASP; optic chiasms; structural brain mutant; verticals]

Received August 19, 1993; revised version accepted September 27, 1993.

The assembly of a functional nervous system requires the numerical matching and precise connection of neuronal populations, which are often spatially distant. This is achieved through the remarkable ability of developing axons specifically to find and follow the pathways leading to their synaptic targets (for review, see Bixby and Harris 1991; Doherty and Walsh 1992; Hynes and Lander 1992) and through the degeneration of surplus cells (Hollyday and Hamburger 1976; Katz and Lasek 1978). The elucidation of the molecular mechanisms responsible for axonal guidance, neural recognition, and the triggering of cell death is therefore essential to an understanding of the basic developmental strategies generating the intricate pattern of neural organization seen in the adult.

In the past few years several studies have provided new insights into the cellular and molecular cues required for correct axonal pathfinding. These include the molecular cloning and characterization of a number of cell surface

Present addresses: ${ }^{1}$ Instituto de Biofísica Carlos Chagas Filho, Universidade Federal do Rio de Janeiro, 21949 Rio de Janeiro, Brazil; ${ }^{2}$ Waite Agricultural Research Institute, University of Adelaide, Adelaide, Australia; ${ }^{4}$ Max Planck Institut für Hirnforschung, D-60528 Frankfurt $/ M 71$, Germany; ${ }^{5}$ Department of Biology, Mount Saint Vincent University, Halifax, Nova Scotia, Canada.

${ }^{6}$ Corresponding author. and extracellular matrix proteins, as well as the identification of factors, diffusible and localized, growth promoting and inhibitory, that have been shown by a number of criteria to be involved in axonal navigation or growth (Rathien et al. 1987; Furley et al. 1990; Burns et al. 1991; Pourquié et al. 1992b; Volkmer et al. 1992). Some of these studies have uncovered the intriguing evolutionary conservation of the basic molecular and cellular mechanisms underlying growth cone guidance and recognition by showing that many proteins implicated in such processes share structural similarities in both vertebrates and invertebrates and often belong to the same superfamilies of genes (Dodd and Jessel 1988; Harrelson and Goodman 1988; Grenningloh et al. 1990; Hortsch and Goodman 1991; Jessel 1988; Rathjen and Jessell 1991; Reichardt and Tomaselli 1991; Takeichi 1991; Walsh and Doherty 1991). On the basis of these similarities the study of axonal growth and pathfinding mechanisms in invertebrates, such as the fruitfly Drosophila melanogaster, is especially useful. The highly sophisticated tools of genetic analysis available in that organism allow the isolation of mutants in which axonal subpopulations display specific projection defects and an in vivo functional dissection of the mechanisms involved (Fessler et al. 1987; Patel et al. 1987; Zinn et al. 1988; Bieber 
et al. 1989; Elkins et al. 1990; Grenningloh et al. 1991; Grenningloh and Goodman 1992).

Cellular suicide often occurs in the absence of stimuli required for survival; therefore, death is assumed to be the default fate of cellular differentiation (Barres et al. 1992; Raff 1992). The elucidation of the mechanisms that underlie the suicide program and its triggering has been started by the isolation of genetic loci in Caenorhabditis elegans that are required for cell death to occur (Ellis and Horvitz 1986) or that inhibit its occurrence (Hengartner et al. 1992). It has been shown recently that the inhibitory function of the ced-9 locus of C. elegans can be mimicked by the human $b c l-2$ gene in transgenic worms (Vaux et al. 1992). This demonstrates a high degree of conservation of the underlying mechanisms throughout evolution.

Cell death also plays a role in the development of the visual system of Drosophila in the optic lobe (Fischbach and Technau 1984) and in the eye imaginal disc (Wolff and Ready 1991; Bonini et al. 1993). Wolff and Ready showed that the roughest ${ }^{C T}\left({ }{ } t^{C T}\right)$ mutation reduces cell death during eye development before and after ommatidial cluster formation, whereas Bonini et al. demonstrated that hypomorphic and loss-of-function mutations in the eyes absent (eya) gene increase the number of cell deaths before the morphogenetic furrow.

In this paper we show that irregular chiasm $C$ (irreC) structural brain mutations and $r s t^{C T}$ affect the same transcription unit. irre $C$ mutations have been reported previously to affect axonal projections in the optic chiasms and function pleiotropically during eye development (Boschert et al. 1990). Therefore, axonal pathway formation in the optic lobe and control of cell death during compound eye development seem to have at least one molecular component in common, the putative ir$r e C-r s t$ protein. irreC-rst encodes a new type of a transmembrane protein of the immunoglobulin superfamily. Although irre $C$ mutations affect the level of transcription, the $r s t^{C T}$ mutation truncates the cytoplasmic domain of the protein. The wild-type protein is required for the normal number of cell deaths in the eye imaginal disc.

\section{Results}

irreC mutations cause axonal projection defects

At the beginning of our study two mutant alleles of the irreC locus were available: the P-element-induced irre $C^{U B 883}$ and the $\mathrm{x}$-ray-generated inversion $\operatorname{In}(1)$ irre $C^{1 R 34}$. Both were originally isolated in our laboratory by purely histological means as a result of serious disorders in the optic chiasms. Deletion constructs without the irre $C$ locus are viable and display optic chiasm defects that are not more severe than those of the mutants (Boschert et al. 1990). The observed optic lobe abnormalities can be grouped into two classes, depending on whether they affect the outer or inner chiasm. In class I defects, axonal bundles originating in the posterior lamina are misrouted on their way toward the ante- rior medulla (Fig. 1A). This defect is correlated with the misplacement of the optic lobe pioneer neurons that apparently establish the outer chiasm pathway (Tix et al. 1989; Boschert et al. 1990). The misrouted bundles form normal terminals in their retinotopic target area, as shown in Golgi-stained preparations of mutants. In class II defects, fiber tracts connecting the medulla to the lobula plate frequently cross the lobula neuropile, instead of running via the inner chiasm (Fig. 1B). In extreme cases, this may result in an apparent fusion of lobula and lobula plate. The two classes of phenotypic abnormalities are not epigenetically coupled, as shown by statistical analysis of their observed frequency in individuals. Their penetrance and expressivity are variable and dependent on the particular allele studied (Boschert et al. 1990).

irreC alleles comap with rst and do not complement the rough eye phenotype

Recombination and deficiency mapping, as well as cytological studies, place irre $C$ in the $3 \mathrm{C} 5$ region of the $\mathrm{X}$ chromosome (Boschert et al. 1990). This interval contains only a few additional genetic functions, roughest (rst) and verticals (vt), and cis-enhancers and cis-suppressors of the adjacent Notch locus (Lefèvre and Green 1972; Welshons and Welshons 1986). The 3C5 region is not necessary for viability. Synthetic null constructs for $3 \mathrm{C} 2-3 ; 3 \mathrm{C} 5-6$ are viable and show rough eyes, the vertical syndrome, and irregular optic chiasms. The same is true for flies hemizygous or homozygous for $D f(1) r s t^{2}$, which removes $3 C 3-4 ; 3 C 6-7$. It is revealing that $\operatorname{In}(1)$ irre $C^{1 R 34}$ mutants show a vertical syndrome and variegate for eye roughness. Furthermore, neither the P-element-induced irre $C^{U B 883}$ allele nor the In(1)irre $C^{1 R 34}$ complement the strong eye roughness caused by the $r t^{C T}$ mutation. $r s t^{C T}$, on the other hand, complements the axonal projection defect of irre $C^{U B 883}$ and irre $C^{1 R 34}$. These genetic data suggested that irre $C$ and $r s t$ are closely associated genetic functions that define two functional aspects of the same genetic unit (Boschert et al. 1990).

\section{Molecular characterization of the irreC-rst region}

A genomic library was constructed in $\lambda$ Dash using DNA from adult flies of the strain irre $C^{U B 883-f 13 C}$. This strain previously had been "cleaned" of most autosomal P elements by backcrossing to FM7 males for 13 generations (Boschert 1991). Screening the library with a complete P-element probe yielded 32 recombinant phages. One of them contained a 2.9-kb P-element insert, and its nonrepetitive DNA was mapped by genomic Southern analysis to the interval $3 \mathrm{C} 5$, between deficiencies $D f(1) / C 19$ and $D f(1) N 71 \mathrm{~h}$, both of which uncover the irre $C$ phenotype (Boschert et al. 1990). The composite physical map of the genomic region flanking the P-element insertion is shown in Figure 2. Except for two small areas of $<1 \mathrm{~kb}$ in length between coordinates -10 and -11 and between -20 and -21 , the cloned region is free from blocks of moderately repetitive DNA.

A single rearrangement in the area -10 to -12 of the 

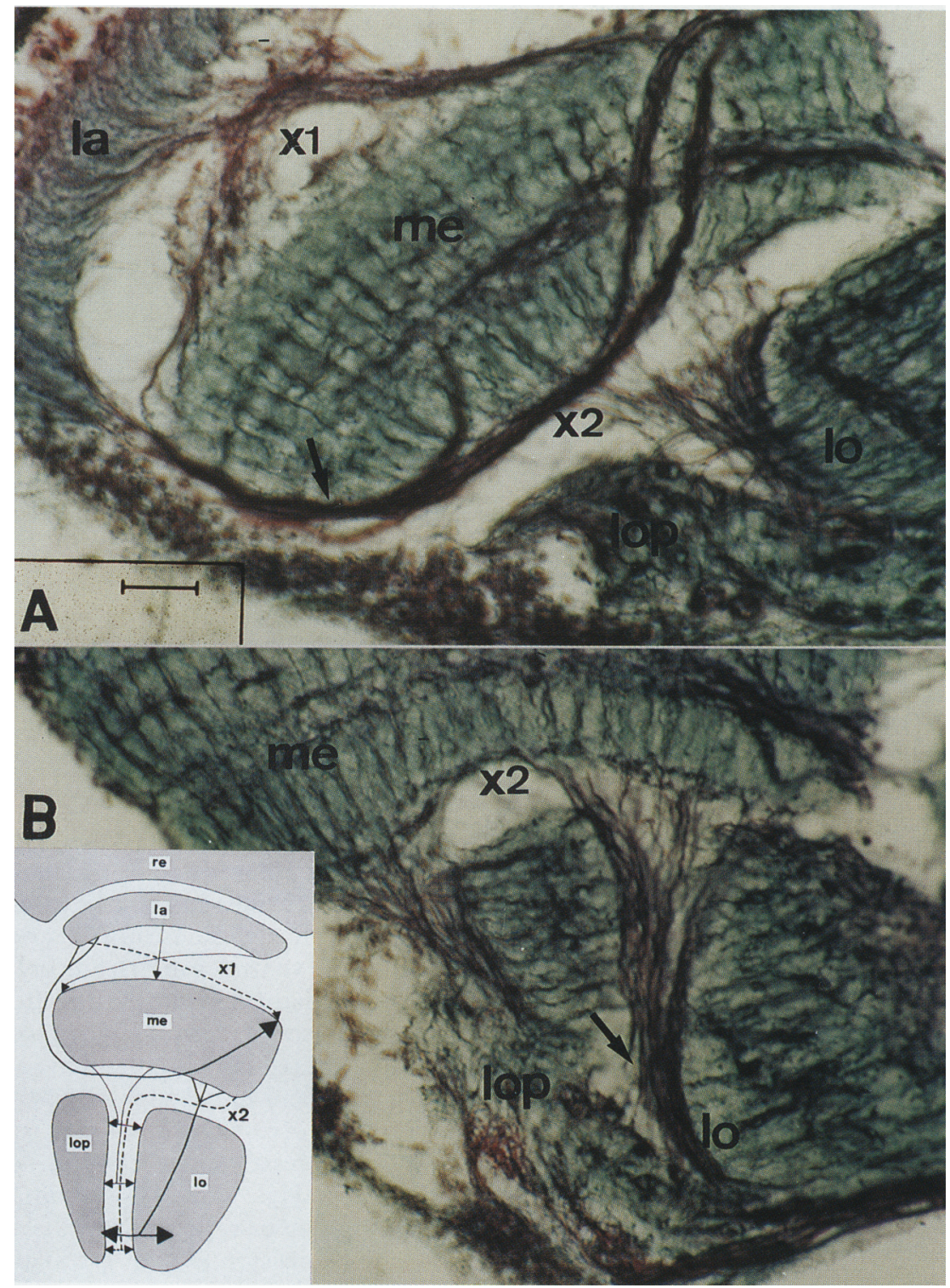

Figure 1. The irregular chiasm phenotypes of the adult optic lobe that led to the isolation of the first mutant irre C allele, irre $C^{U B 883}$. (A). Class I defects: Axon bundles from the posterior lamina (la) do not project via the first optic chiasm $(\mathrm{x} 1)$ into the anterior medulla (me). Instead, they curve behind the medulla neuropile (arrow $)$ into the second optic chiasm $(\mathbf{x} 2)$, and then penetrate the medulla from proximal to distal to finally reach their normal retinotopic projection area. Long retinal fibers, as well as axons of lamina monopolar neurons, form normal terminals despite their abnormal routes (Boschert et al. 1990). (B) Class II defects: Fibers from the anterior medulla (arrow) cross the lobula (lo) neuropile to reach the lobula plate (lop). (Inset) Scheme of normal (thin continuous lines) and ectopic fiber (thick continuous lines) tracts in the optic chiasms of irre $C$ mutants. Broken lines indicate the wild-type routes of the misrouted fiber bundles. Bar, $25 \mu \mathrm{m}$. walk (Fig. 2) was mapped in the DNA of $\operatorname{In}(1)$ irre $C^{1 R 34}$ flies. In situ hybridization to squashes of $\operatorname{In}(1)$ irre $C^{1 R 34}$ chromosomes using wild-type probes from both sides of the rearranged area confirmed that it was the proximal breakpoint of the In(1)irre $C^{1 R 34}$ inversion.

Finally, two small rearrangements were detected in DNA derived from flies carrying the $F M 7 c$ chromosome, in the area between +10 and +20 (Fig. 2). Because FM7c-irreC heterozygotes have regular optic chiasms, these lesions do not seem to affect the irreC-rst genetic unit.

\section{cDNA isolation and transcriptional analysis}

The transcriptional activity of the cloned region was assessed initially by reverse Northern analysis (Pirrota et al. 1983). Genomic fragments giving positive signals were detected in the region between coordinates 0 and -23 of the walk. A 5.0-kb SalI fragment (coordinates -21 to -16 ; Fig. 2) giving the strongest signal in reverse Northern analysis was used to screen cDNA libraries from all developmental stages. Several cDNAs varying in length from 0.8 to $3.2 \mathrm{~kb}$ were isolated from a randomly primed embryonic $\lambda$ gt 11 library (kindly provided by Dr. B. Hovemann, Lehrstuhl für Biochemie der Ruhr-Universität, Bochum, Germany), whereas one cDNA of $\sim 4.1$ $\mathrm{kb}$, denoted HB3, was obtained from an adult head $\lambda \mathrm{gtl} l$ library (kindly provided by Dr. E. Buchner, TheodorBoveri-Institut, Würzburg, Germanyl. All cDNAs showed extensive cross-hybridization and overlapping restriction patterns and, therefore, may originate from a single transcription unit, the primary transcript of which is $\geqslant 23 \mathrm{~kb}$ long. A $0.9-\mathrm{kb}$ EcoRI-SstI cDNA fragment [distal to the In(1)irre $C^{1 R 34}$ breakpoint; Fig. 2] recognizes a 

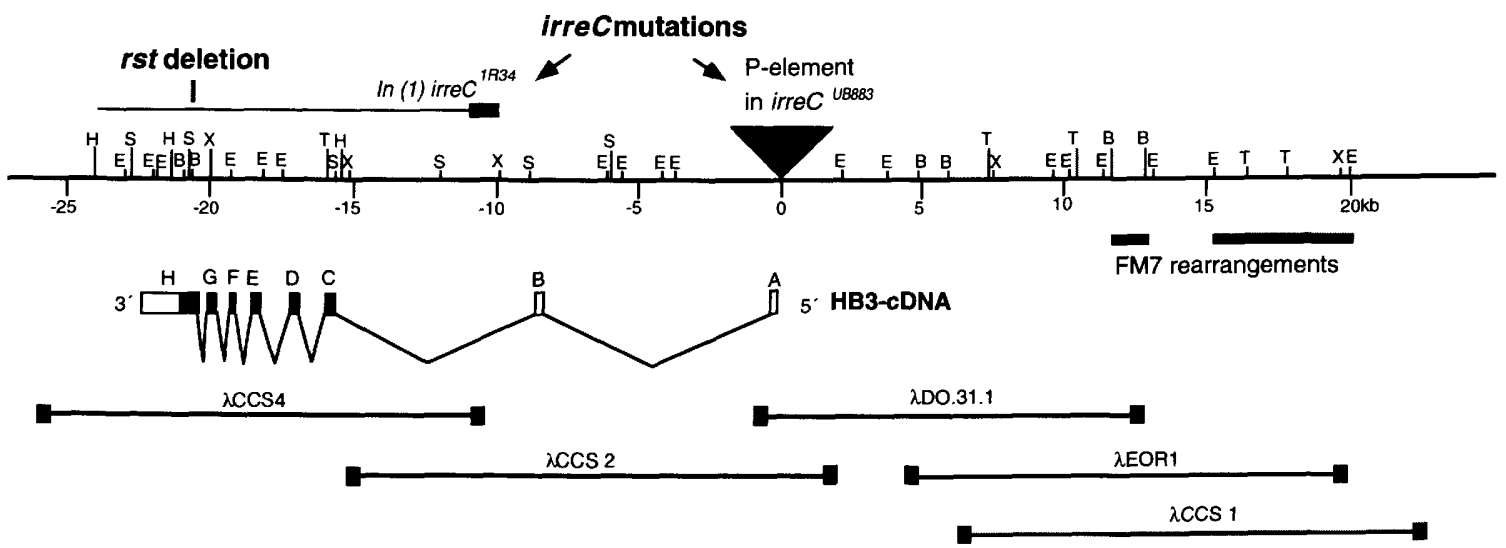

Figure 2. Physical and transcriptional map of the irreC-rst locus. The P-element insertion irre $C^{U B 883}$ marks the starting point of the chromosomal walk (position 0). The intron-exon organization of the largest cDNA isolated, HB3, is depicted. The P-element insertion is $292 \mathrm{bp}$ upstream of the $5^{\prime}$ end of that cDNA. The inversion breakpoint In(1)irre $C^{1 R 34}$ interrupts the primary transcript between exons $B$ and $C$. The single, large open reading frame of $\mathrm{HB} 3$ is contained in exons $\mathrm{C}$ to $\mathrm{H}$ (black bars). In exon $\mathrm{H}$ it is disrupted by the ${ }_{r s t}{ }^{C T}$ deletion. The extent of some $\lambda$ clones is shown as well. Restriction sites: $(B)$ BamHI; $(E) E c o R I ;(H)$ HindIII; $(S)$ SalI; $(T) S s t I ;(X)$ Xhol.

major poly $(\mathrm{A})^{+}-\mathrm{mRNA}$ species of $\sim 5.0 \mathrm{~kb}$, present throughout development, but peaking at embryonic and pupal stages (Fig. 3).

In situ hybridizations to embryonic whole mounts with this probe reveal that embryonic irreC-rst expression is temporally and spatially regulated, that is, in late embryonic stage 11 hybridization signals are detected in lateral mesodermal cell clusters, in midline cells of the nervous system, in cell clusters in the mandibular, maxillar, and labial buds, and in the clypeolabrum (Fig. 4A).

In situ hybridizations to first-, second-, and early thirdinstar larvae show only weak expression. However, in

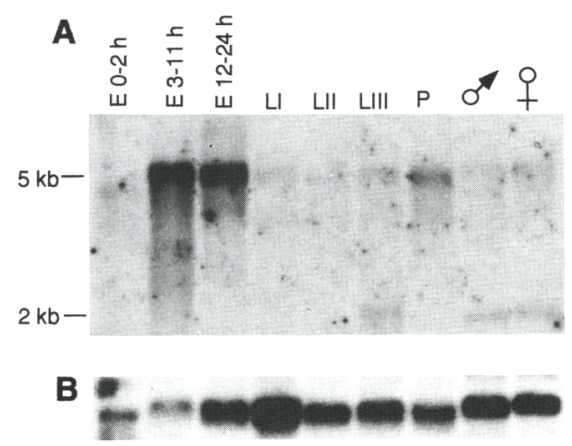

Figure 3. Developmental Northern blot analysis. Poly $\mid \mathrm{A})^{+}-$ mRNA from different developmental stages [lembryonic) E 0-2 hr; E 3-11 hr; E 12-24 hr after egg deposition; (LI, LII, LIII) first-, second-, and third-instar larvae; (P) pupae; male and female adult flies]. (A) The 0.9-kb EcoRI-SstI fragment from cDNA HB3 recognizes a major RNA species of $\sim 5.0 \mathrm{~kb}$, present throughout development, but peaking at embryonic and pupal stages. Several minor bands can also be visualized (under high stringency). (B) Control using Drosophila ras cDNA (Mozer et al. 1985). late-third instar larvae strong signals in wild-type imaginal discs and in the outer optic anlagen can be observed (Fig. 4B-D). Expression in the eye imaginal disc (Fig. 4C) starts just in front of the morphogenetic furrow (arrowheads). The central brain and ventral ganglia are only weakly labeled. In the pupal central brain $(36 \mathrm{hr}$ after puparium formation) no transcripts can be detected, whereas the intensity of expression is very high and stays so $\$ 72 \mathrm{hr}$ in the lamina and in subpopulations of medullar cells (Fig. 5A). At $36 \mathrm{hr}$ strong expression in the wild-type-developing retina is restricted to cells in between the ommatidial clusters (Fig. 5B) (i.e., to presumptive secondary and tertiary pigment cells and to cells of the bristle complex). Gene expression is then gradually down-regulated in the retina and no more transcripts can be detected $72 \mathrm{hr}$ after puparium formation.

No transcripts could be detected in $\operatorname{In}(1)$ irre $C^{1 R 34}$ at any developmental stage (data not shown). irre $C^{U B 883}$ embryos, larvae, and pupae, however, do express mRNA from the locus, albeit at a variable and strongly reduced level (Figs. 4D and 5C). The expression pattern in $r s t^{\mathrm{CT}}$ optic lobes seems to be normal. In the $r s t^{C T}$ retinae, there is strong expression in between the ommatidial clusters (Fig. 5D).

We showed previously (Boschert et al. 1990) that the irre C-rst gene product is required in at least three independent places: in the developing retina and in different cell populations involved in the formation of the first and of the second optic chiasms. The pattern of gene expression obtained with the HB3-derived probe fulfills these requirements. The pupal expression in cells between the ommatidia is especially reassuring as surplus cells of this population are normally eliminated by programmed cell deaths that do not occur in ${ }^{2 s t}{ }^{C T}$ (Wolff and Ready 1991). 


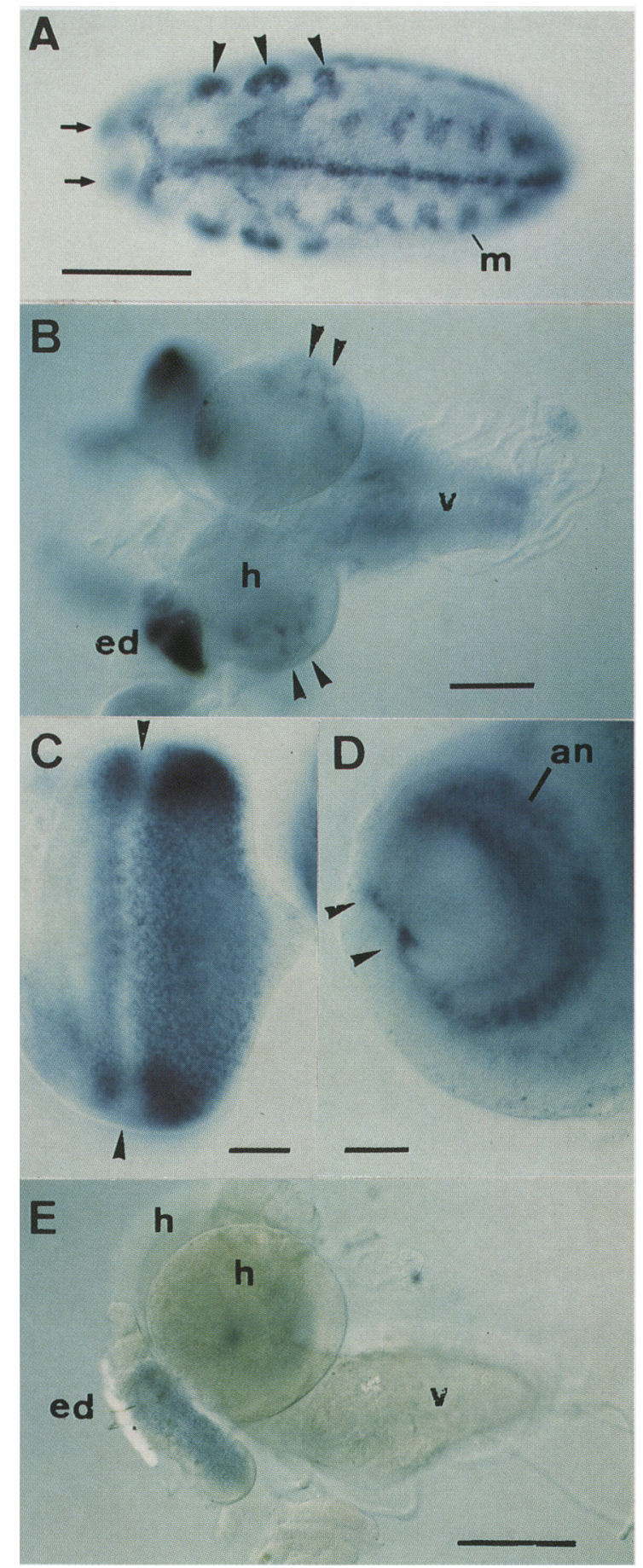

Sequence analysis of $c D N A H B 3$ from the irreC-rst region

Sequence determination of CDNA HB3 showed it to be 4115 nucleotides in length and assembled from 8 exons. Complete genomic sequencing of the regions present in cDNA HB3 allowed the exon-intron borders to be identified precisely (Fig. 6). Exon 1 is incomplete and extends
Figure 4. Embryonic and larval tissue in situ hybridizations using the 0.9-kb EcoRI-SstI fragment from cDNA HB3 labeled with digoxigenin. (A) Late stage 11 wild-type embryo. mRNA expression is in the buds of the gnathal segments (arrowheads), in cell clusters of the clypeolabrum (arrows, out of focus), in midline cells of the ventral nervous system, and in segmentally repeated mesodermal cell clusters $(\mathrm{m}) .(B)$ Dorsal view of whole mount of wild-type late third-instar larval central nervous system with the brain hemispheres $(\mathrm{h})$, the ventral nerve cord $(\mathrm{v})$, and the eye imaginal discs (ed). Note strong expression in the eye discs. From this perspective, expression is seen in two small cell populations of the optic lobe anlagen (arrowheads). $(C)$ View onto a wild-type eye imaginal disc. Anterior is to the left. The arrowheads point to the morphogenetic furrow. Expression starts just in front of it. (D) Lateral view onto a wild-type thirdinstar brain hemisphere. A crescent-like expression pattern is visible in the outer optic anlage (an). Arrowheads point to the same cells as in $B .|E\rangle$ Lateral view of central nervous system and eye imaginal disc from homozygous irre $C^{\text {UB83 }}$ late thirdinstar larva. The eye imaginal disc still shows some expression, although much weaker than in wild type. Bars in $A, B, E, 100$ $\mu \mathrm{m}$; bars in $C, D, G, 25 \mu \mathrm{m}$.

at least $\sim 0.3 \mathrm{~kb}$ farther into the $5^{\prime}$ direction, as is shown by preliminary sequencing of other cDNAs and of the genomic sequence. The AT-rich $1.62-\mathrm{kb}$ untranslated $3^{\prime}$ end of cDNA HB3 contains six ATTTA repeats that are thought to function as recognition signals for rapid mRNA degradation (Shaw and Kamen 1986). A single polyadenylation site is found at position 4087, followed by a poly $(A)$ stretch. The direction of transcription is 


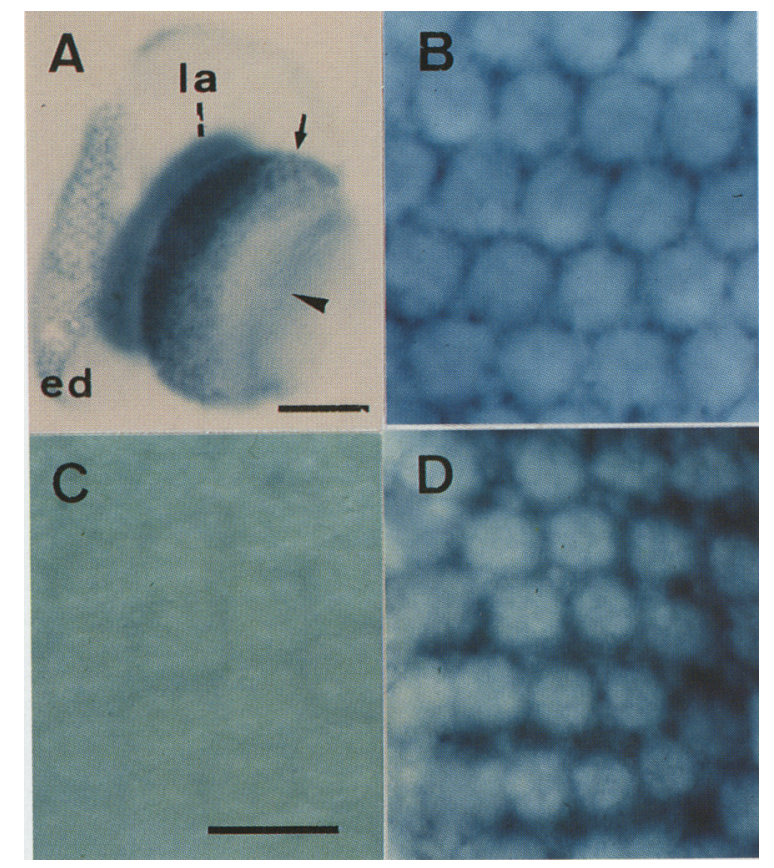

Figure 5. Pupal tissue in situ hybridizations using the $0.9-\mathrm{kb}$ EcoRI-SstI fragment. (A) Whole mount of eye imaginal disc (ed) and the optic lobe [60 hr after puparium formation (apf)]. At that stage expression in the lamina (la) is strongest. Expression in the medulla is patchy (arrow). Some label can also be detected at the level of inner optic chiams (arrowhead). No expression is seen in the central brain. $(B)$ Apical surface of wild-type eye imaginal disc ( $36 \mathrm{hr}$ apf). irreC-rst expression is between the ommatidia. $(C)$ irre $C^{U B 883}$ eye imaginal discs of the same age show only very weak expression. $(D)$ Expression pattern in $r s t^{C T}$ mutants. The deletion does not interfere with transcription. Bar in $A, 25 \mu \mathrm{m}$; bars in $B, C, D, 50 \mu \mathrm{m}$.

from proximal to distal, relative to the centromere of the chromosome (see Fig. 2). The only long open reading frame in HB3, which also coincides with the maximum coding probability area, as determined by the algorithm of Fickett (1982), starts at position 205 and ends at position 2497 , potentially encoding a 764 -amino-acid polypeptide. The beginning of the open reading frame is immediately preceded by the four nucleotides CAAC, which match the consensus sequence for Drosophila translational initiation sites (Cavener et al. 1987). The codon preference is in good agreement with a codon usage table for Drosophila proteins. Together, these fea- tures strongly suggest that this open reading frame codes for the irreC-rst protein. The existence of another translated open reading frame is very unlikely as all reading frames are interrupted by many stop codons beyond the limits of this open reading frame.

\section{The irreC-rst $H B 3$ protein shares structural similarity with members of the immunoglobulin superfamily}

A hydrophilicity plot (Kyte and Doolittle 1982) of the derived polypeptide encoded by CDNA HB3 is shown in Figure 7A. Two strongly hydrophobic peaks can be seen. The first, corresponding to residues $1-19$, has the characteristics of a signal peptide, whereas the second, comprising amino acids $529-556$, is likely to be a membranespanning region. The protein, therefore, seems to be an integral membrane protein, with a 509-amino-acid-long extracellular portion, a single transmembrane domain, and a cytoplasmic tail of $\sim 208$ residues at its carboxylterminus. Five potential amino-glycosylation sites, matching the consensus sequence $N[P][S T][P]$, were found in the extracellular domain at positions 211, 313, 393,400 , and 507 . The predicted molecular mass for the nonglycosylated mature protein is $83.1 \mathrm{kD}$.

Figure 7B shows the proposed secondary structure of the putative protein encoded by HB3. Visual inspection of the proposed extracellular region, as well as sequence alignments, showed it to be composed of five repeats of a structural motif containing characteristic arrangements of cysteines and tryptophans, as well as other conserved amino acids typically found in members of the immunoglobulin superfamily (Williams and Barclay 1988; Fig. 7C). The length of the repeats varies from 82 to 100 amino acids, and the spacing between the two cysteines in each domain ranges from 60 residues, in the second and largest one, to 42 , in the fourth and smallest one (Fig. $7 \mathrm{~B}, \mathrm{C}$ ). The size and the conserved amino acids surrounding the cysteines make all five domains similar to the C2-type of immunoglobulin domains (Williams and Barclay 1988).

Similarity searches, performed with the FASTA (Pearson and Lipman 1988) and BLAST (Altschul et al. 1990) programs in the GenBank, EMBL, and NBRF protein data bases, showed that the extracellular portion of the HB3 protein is related to a number of proteins of the immunoglobulin superfamily (Table 1 ), most notably to the three chicken axonal surface proteins DM-GRASP

Figure 6. Complete nucleotide and deduced amino acid sequence of cDNA HB3. Four-digit numbers give position of nucleotides; three-digit numbers give amino acid position. Nucleotide level: The intron-exon boundaries are indicated by small vertical arrows. Note that the second intron-exon boundary is just in front of the consensus sequence CAAC for a Drosophila translation start site (boxed); the last splice site is in front of the transmembrane domain. In the 3 '-untranslated tail six ATTTA sequences thought to be involved in mRNA degradation (Shaw and Kamen 1986) are underlined. Near the 3 ' end a putative polyadenylation site is found (AATAAA, doubly underlined). Protein level: Cysteines and tryptophans are boxed, as are the signal peptide (amino acids 1-19) and the putative transmembrane domain (amino acids 529-556). Five putative amino-glycosylation sites $[\mathrm{N}(\mathrm{P})[\mathrm{ST}](\mathrm{P})]$ are dotted. In the putative extracellular part of the protein, a glycine-rich stretch is underlined (amino acids 245-262), as is an opa-like sequence in the intracellular domain (amino acids 637-658). Three putative S/T phosphorylation sites in the intracellular domain are circled. The nine tyrosines of the intracellular domain are enclosed in inverted triangles. 
Molecular characterization of irreC-roughest

0001 CGTTAGTGCCAGTGGCCGGTCAGAGTCAGTTAAAAATATATATGCATATAAGAGGACTAAGGAGCCGAAATTGTTTAAATTGATTACAAACAAACAGTA 0100 TCTCAAGGCCCAAAGGAGCAAGGAGTAGAAAGGAGGAAATAAAGAAGAGTGAGAAAGTGACACCCAAGACTTCAGTTCTGTCATTGAAAAGGTGTTGA 0199 ACCAADATGTTGCACACGATGCAGCTGCTCCTGCTGGCCACTATTGTGGGCATGGTCAGGAGCTCGCCGTACACGAGCTATCAGAACCAACGGTTCGCC

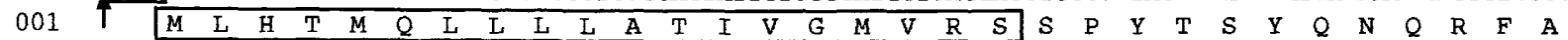
0298 ATGGAGCCGCAGGATCAGACGGCAGTGGTTGGGGCCAGGGTAACGCTACCCTGCCGAGTGATCAACAAACAGGGCACGCTCCAATGGACCAAGGATGAC

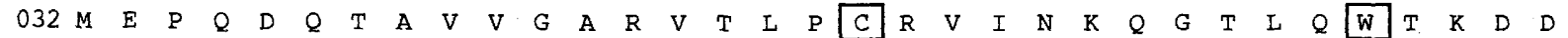
0397 TTTGGACTTGGCACGTCCCGGGATCTGAGTGGATTCGAACGCTACGCGATGGTGGGCAGTGACGAGGAGGGTGACTACTCCCTGGACATTTATCCAGTG $\begin{array}{llllllllllllllllllllllllllllllllllllll}065 & F & G & L & G & T & S & R & D & L & S & G & F & E & R & Y & A & M & V & G & S & D & E & E & G & D & Y & S & L & D & I & Y & P & V\end{array}$ 0496 ATGCTGGACGACGATGCTCGTTACCAGTGCCAAGTGAGCCCAGGTCCCGAGGGCCAACCAGCCATTAGGTCCACATTCGCCGGATTGACGGTGCTCGTT

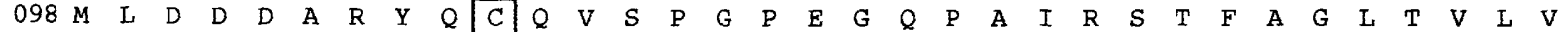
0595 CCGCCCGAGGCGCCCAAAATCACACAGGGCGACGTCATCTATGCCACCGCGGATCGCAAAGTGGAGATCGAGTGCGTTTCGGTTGGCGGAAAGCCGGCT $\begin{array}{llllllllllllllllllllllllllllllllllll}131 & P & P & E & A & P & K & I & T & Q & G & D & V & I & Y & A & T & A & D & R & K & V & E & I & E & C & V & S & V & G & G & K & P & A\end{array}$ 0694 GCTGAGATTACCTGGATTGATGGCCTGGGCAATGTCCTTACGGATAACATTGAGTACACGGTGATACCGCTGCCCGATCAGCGACGCTTTACGGCCAAG

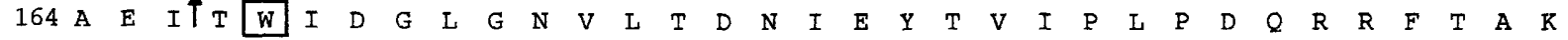
0793 TCCGTCCTGCGATTGACCCCAAAAAGGAACACCACAACACGAACTTCAGTTGCCAGGCGCAGAACACGGCGGACCGCACCTATCGCTCGGCGAAAATA

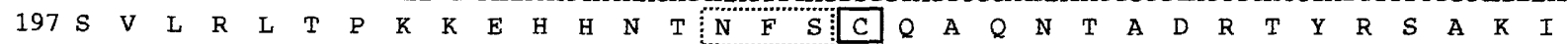
0892 CGTGTCGAGGTGAAATATGCCCCCAAGGTGAAGGTGAATGTGATGGGCTCGCTTCCCGGCGGTGCAGGTGGTTCGGTTGGTGGTGCAGGCGGTGGCAGT

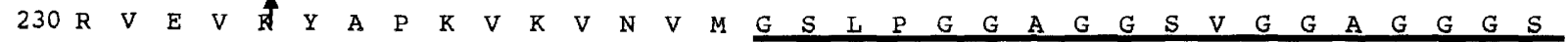
0991 GTCCACATGAGCACCGGTTCCCGTATTGTGGAGCATTCGCAGGTGCGCTTGGAGTGCCGGGCAGATGCGAATCCCAGCGATGTCCGGTACCGCTGGTTC

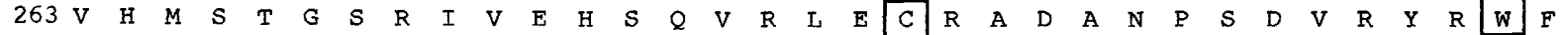
1090 ATAAACGACGAACCGATCATCGGCGGCAGAAGACAGAGATGGTGATACGCAATGTGACTCGCAAGTTCCACGATGCGATTGTCAAGTGCGAGGTGCAG

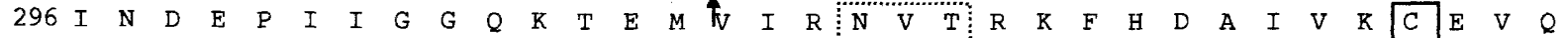
1189 AATTCCGTGGGCAAGAGTGAGGACAGCGAAACCCTTGACATAAGCTATGCTCCCAGTTTCCGGCAGCGACCACAGTCAATGGAGGCGGACGTTGGCAGC $\begin{array}{lllllllllllllllllllllllllllllllllll}329 & N & S & V & G & K & S & E & D & S & E & T & L & D & I & S & Y & A & P & S & F & R & Q & R & P & Q & S & M & E & A & D & V & G & S\end{array}$ 1288 GTGGTGTCCCTAACCTGCGAGGTGGACAGCAATCCGCAGCCGGAGATCGTCTGGATACAGCATCCCAGTGACCGGGTGGTGGGCACCAGCACAAATCTC

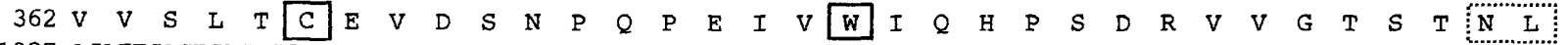
1387 ACATTCAGTGTGAGCAATGAGACGGCTGGAAGGTACTACTGCAAGGCCAATGTACCCGGATACGCTGAGATTTCGGCAGATGCCTATGTCTATCTGAAG

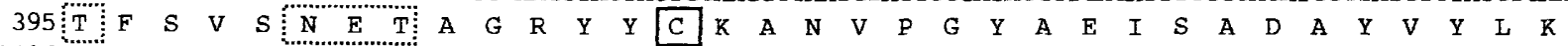
1486 GGCTCGCCGGCGATTGGATCGCAGAGGACACAGTACGGATTGGTGGGAGATACGGCTCGGATCGAATGCTTTGCCAGCAGTGTTCCTCGAGCCCGTCAC

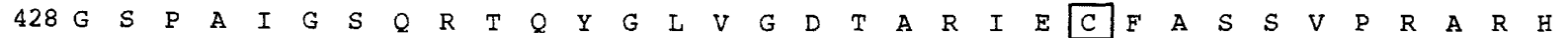
1585 GTCTCGTGGACGTTCAACGGTCAGGAGATCAGCTCGGATCGGGACACGACTATTCGATTCTGGTTGATGCCGTGCCGGGTGGCGTAAAGAGCACGCTT

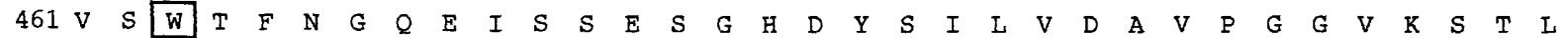
1684 ATCATTAGGGACAGCCAGGCCTACCACTACGGAAAGTACAACTGCACGGTGGTCAACGATTACGGCAACGACGTGGCCGAGATTCAGCTGCAAGCCAAG

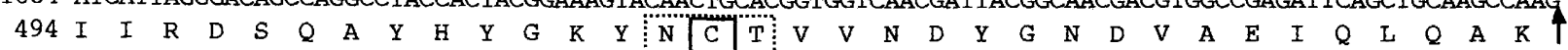
1783 AAGAGCGTTTCCCTGCTGATGACAATTGTGGGCGGCATTTCGGTGGTGGCCTTCCTGCTGGTGCTGACCATTTTGGTTGTGGTCTACATCAAGTGTAAG

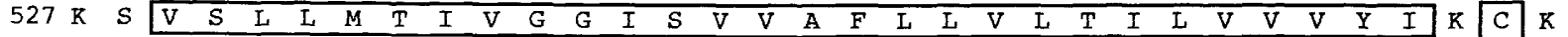
1882 AAGCGCACCAAGCTGCCGCCAGCGGATGTGATAAGCGAGCATCAGATCACGAAAAATGGCGCGTTAGCTGCAAACTGGAACCAGGCGACCGGACCTCG

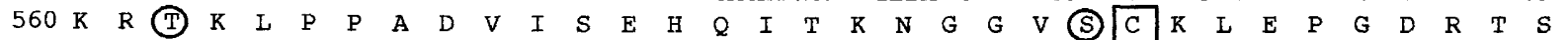
1981 AACTACAGCGATCTAAAGGTGGACATTTCGGGCGGCTATGTGCCCTACGGCGACTACAGTACGCACTACAGTCCGCCTCCGCAATACCTGACCACCTGT

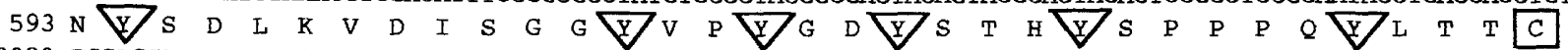
2080 TCGACGAAATCCAATGGCAGCTCGACCATTATGCAGAACAACCATCAGAACCAATTGCAACTACAGCAGCAGCAGCAACAGAGCCACCACCAGCACCAC

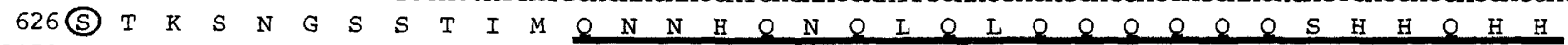
2179 ACACAGACGACGACCCTGCCGATGACCTTCCTGACCAACAGCAGCGGTGGCAGCTTGACTGGCAGTATTATTGGATCCCGTGAAATTCGCCAGGACAAC

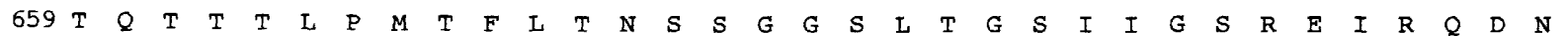
2278 GGGCTGCCCAGTCTGCAGTCGACCACCGCCTCGGTGGTTAGCTCATCGCCGAATGGCAGCTGCAGCAATCAGAGCACCACTGCCGCCACCACCACCACC $\begin{array}{lllllllllllllllllllllllllllllllllll}692 & G & L & P & S & L & Q & S & T & T & A & S & V & V & S & S & S & P & N & G & S & C & S & N & Q & S & T & T & A & A & T & T & T & T\end{array}$ 2377 ACCCACGTGGTGGTGCCCAGCTCGATGGCCCTGAGTGTGGATCCCCGCTATAGCGCCATTTACGGCAATCCCTATCTTAGGTCCTCCAACTCGTCGCTG

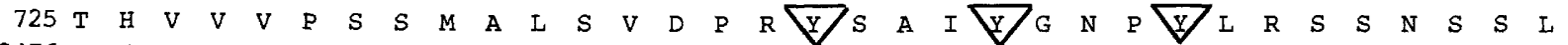
2476 CTGCCGCCACCCACTGCCGTTTAGGGTGGACCAGCACCGTCCACCACCAACACCACCAACACACCACCACCACCACTGCCAACAACAACGATGACCCAC $\begin{array}{llllllllllll}758 & \text { L } & \text { P } & P & P & T & A & V\end{array}$

2575 TGAGCCACGCTAAGACTGATCTCACAAGGAACCGAGGCCCGGCGGCTGCTTTTGGGGGGGTATCACTGTTCGTGGTGGTGCGTTTTTCAGCTACCAAAA 2674 TTCGAATTGCTTAGGTTAGGCACTTAGCTCACATACATCCGATTATATAGGCATAATCGTAAGCTGATCTTTAGCATCATCATTTCTATAGTCCTTAGG 2773 TCTAGGGTATTTTATTTTATGTTTTTTTTTTTTTTTGTCGTTTTTGTGTTCTTAGCTTAAGGATCTTACAGTAGGCTAATATCCCCAGTTTGATCTAGA 2872 GAGAGACTAAGCTTCAAAGAATGAGTGTTAAGCATTTACAGAACAAAAAACAAAAAACAAATCTTAGGAAGATTAGAAAGTTTTACTGCTTGTTGAGAA 2971 AACGCCTTAATGTACTAGTTAACTGATTGGGGATTTAACCTCCAGTTACAAGAAAAAAAAAAAAACTGGTTTTCTTGGGGGCGGGGATATGCGAGAGCC 3070 GTTTTGAACATGTTCTCTGATTTCATATAATGTTTCAAATATTATTTTCGATTCAAATATTATTTCCGTGTCTCTTATTCTCAAAACTTAATGCTCTTC 3169 TATTTTTAAAAAATTGATTGCTATTTTTTGTACAGTGTACATGTGTACATGAAACTTTAGAACTATTTGATTTTGAAATCCCGAGAATATTCCTTCGT 3268 CAAAAACAGCTGCCCTATATAATCCGCAAAAAATATATAGAAAGTAATTGAAAGATTCAATTTTATGTATACACAGCTATAGTATATGCTAAATGT 3367 TAATGATATATATATATATATATACAACAAGCATGAAGACATTCAGTTGAATGGATAGCGAGTAAGCGAACGAAATGCCAAAGTACCTGATAGTATTTIA 3466 AGTAGGGGGTGGGAAAGTCTTTGGATCGGTACCGCCCGCCATTAACTTCTTCTGAATTATGTAGCATTATCTTTTCTCGCCGGAATTCTAAGCTATGAC 3565 TTGGGATTCGATAGTGTGT"T"TACGAT"TAAATAAATATAGAAGCTAGATCTTGACAGTCGCCTTAACT"TATGACACGCCCATACATCTCAAAACGCCCA 3664 TGCAAATATAGGAAAAGAAACAAAAATGAGAGCGTAAACGTATTCAATTCGTCAGTTCAATTGTGCTAAGTGTACTTCTAAGTGTATAACGTTCTAAT 3763 TATCCTAGTTGTAGCCTAACTAATGATAGACACGCATATTTAAAGTATAGACCTAGCCCTAGATATACATACATGCATTTTTTTTCATAGGCCTAAGCA 3862 TTATATTTTGATAAGCAGTTATTTCGTCAAAGGAGCCCCTGAAAAGTAACATTACTATTTCATTTTGCTATATTTATTAGCTGTGGGTATTTTATTA 3961 GTGTCGCCAATTAAGCGCGAAACGAACAAATGTTTTTTGTTTACAAAATGCAAATGATAAAAGCAAATAAGCAGCATGAAACACACACAAAGTTAAACA 4060 CGAAAACAAAAGCAAAAAAAAACTGAATAAAAATTTATTGAAAAAAAAAAAA

Figure 6. (See facing page for legend.) 
A

B

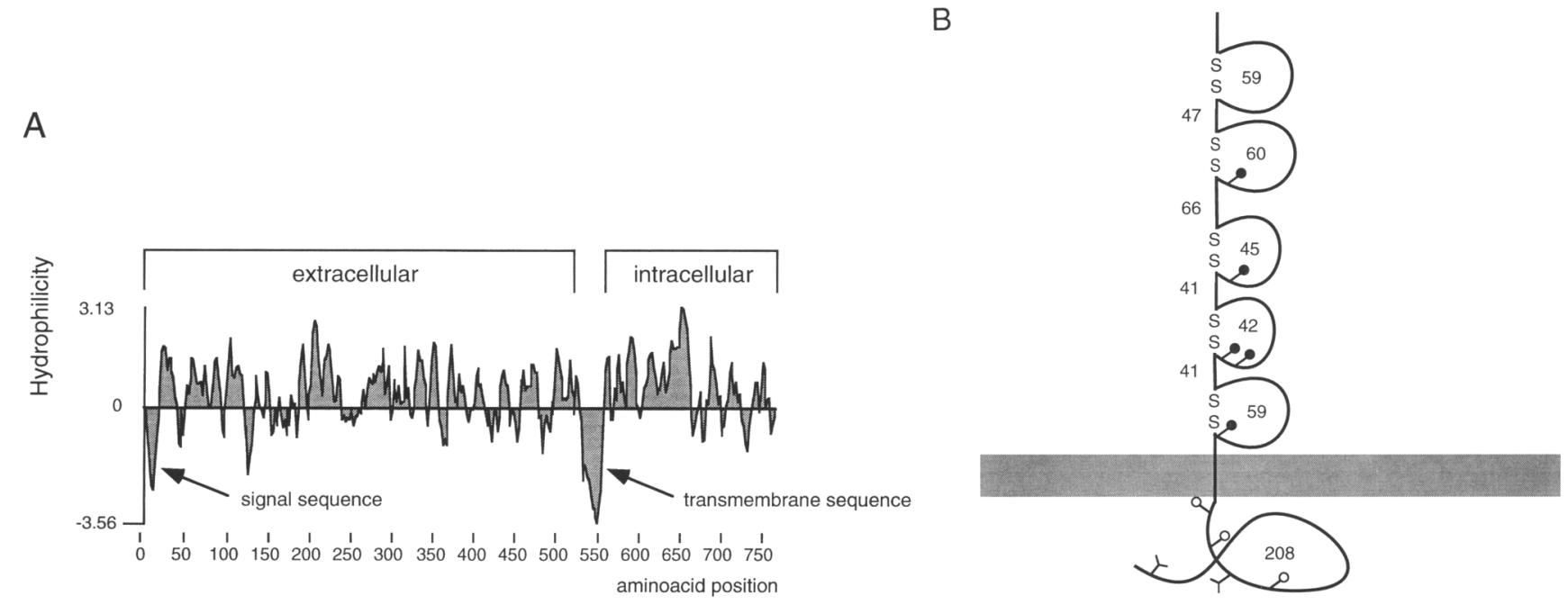

C

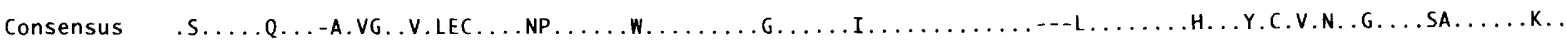

HB3-D1 QRFAMEPDDQT-AVVGARVTLPPRVI-NIKQG-TLQNTKD--DFGLGTSRDL SGFERYAMVGSDEEGDYS[DIYPVMLDDDARYQCQVISPGPEGQPAIRSTFAGLT AP-KITQGDVIYATEDRKWEIECUSVGGKPAAEIT IDGL GNVL TDNIEYTVTPLPDQRRFTAKSV - - L RLTPKKEHANTNFSCQAQNTADRTYR SAKIRVEVKY AP - HIT

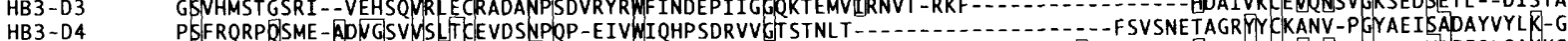

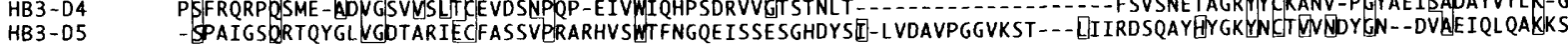

$\mathrm{D}$

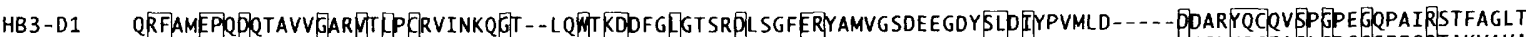

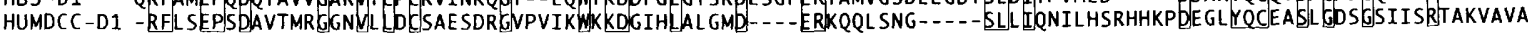

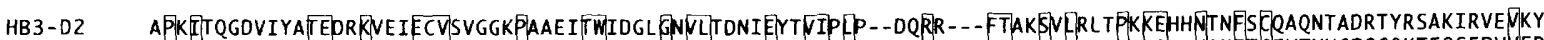
DMGRASP-D2 QDEILHQADFLETEKL KML GECVVRDSYPE GNVTWYKN-GRVLQPVEEVVVINLRKVENRSTGLFTMTSSLDYMPTKEDANAKETEIVTYHGPSGQKTIQSEPVVFD

HB3-D3 GSWHMSTGSRIVEHSQVRDEFRADANPSOVRYRWFINDEPIIGGQKTEMVIRNVTRKFFDAIVKCEVQNSVGKSEDSETLDISPA

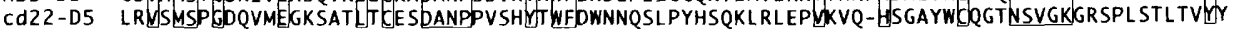

HB3-04 PSFRRRPQSMEAOVGSVVSLTCEVDSNPQPEIVWIQHPSDRRTVGTSTNRTF-SVSNETAGRFYYCKANVPGYAEISADAYVYTIKG

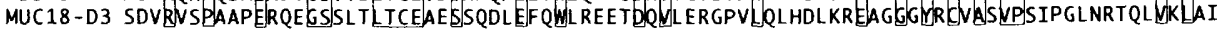

HB3-D5 SPAFIGSORTOPGL VGDTARTEEFASSVPRARHVSWTFNGEEISSESGHDYSILVDAVPGGVKETLIIRDSOAYHYGKYNCTVVNDYGNDVAEIQLRAKKS

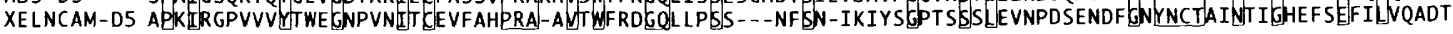

Figure 7. Characteristics of the putative HB3 protein. $(A)$ Hydrophilicity plot showing two strongly hydrophobic regions: $(1)$ the putative signal sequence at the amino terminus from amino acids $1-19$, and $(2)$ the putative transmembrane domain from amino acid 531 to 556. (B) Putative secondary structure of the HB3 protein with five extracellular immunoglobulin domains and a large intracellular domain. The numbers of amino acids per segment are given. Note the relatively long distance between the second and the third domain that is caused by a glycine-rich spacer. (O) Putative amino-glycosylation sites of the extracellular domain are marked (O) Putative serine/threonine phosphorylation sites of the intracellular domain. The positions of putative phosphotyrosines (Y) are also given. (C) Alignment of the five extracellular immunoglobulin domains of the HB3 protein using the Clustal V program. The consensus sequence is shown above. The fitting amino acids are boxed. (D) Each of the five HB3 domains aligns best with an immunoglobulin domain of another vertebrate member of the immunoglobulin superfamily: HB3-D1 with domain 1 of the human DCC gene product (Fearon et al. 1990); HB3-D2 with domain 2 of the chicken DM-GRASP protein (Burns et al. 1991), HB3-D3 with domain 5 of the human B-cell receptor cd22 (Stamenkovic and Seed 1990), HB3-D4 with the third domain of the human melanoma marker MUC18 (Lehmann et al. 1989), and HB3-D5 with the fifth domain of Xenopus NCAM. Identities are boxed.

(Burns et al. 1991), BEN (Pourquié et al. 1992a), and SC1 (Tanaka et al. 1991), all three of which are likely to be encoded by the same gene. The HB3 protein is also similar to human myelin-associated glycoprotein (MAG; Salzer et al. 1987), rat TAG-1 (Furley et al. 1990), human melanoma marker MUC18 (Lehmann et al. 1989), NCAM (Barthels et al. 1987; Cunningham et al. 1987), human poliovirus receptor (Mendelsohn et al. 1989), chicken axonal protein SPF3 (Gennarini et al. 1989), and Drosophila neuroglian (Bieber et al. 1989). The removal of the spacer can dramatically increase some of the optimized scores and the extent of the alignment of the HB3 protein, especially with DM-GRASP/BEN/SC1 and MAG. However, none of those molecules aligns well through the whole length of the HB3 protein. Particularly, no significant homology is found to the intracellular domain. Furthermore, each of the immunoglobulinlike domains of the HB3 protein shows best similarity to a domain of a different member of the immunoglobulin superfamily (Fig. 7D). 
Table 1. List of immunoglobulin-like proteins showing significant similarity to the irreC-rst $H B 3$ protein

\begin{tabular}{lccccccc}
\hline & \multicolumn{3}{c}{ HB3 protein complete } & & \multicolumn{3}{c}{ HB3 protein without spacer } \\
\cline { 2 - 3 } Name & $\begin{array}{c}\text { identity } \\
(\%)\end{array}$ & $\begin{array}{c}\text { no. of aligned } \\
\text { residues }\end{array}$ & $z$ score & $\begin{array}{c}\text { identity } \\
(\%)\end{array}$ & $\begin{array}{c}\text { no. of aligned } \\
\text { residues }\end{array}$ & $z$ score \\
\hline DM-GRASP & 25.9 & 166 & 20.6 & 21.1 & 483 & 20.7 \\
MAG & 23.5 & 307 & 10.8 & 23.6 & 428 & 17.1 \\
F3 & 24.0 & 275 & 16.7 & 22.1 & 357 & 16.9 \\
MUC & 21.0 & 415 & 16.3 & 21.2 & 400 & 16.4 \\
POR & 22.3 & 251 & 14.1 & 21.7 & 355 & 14.2 \\
NCAM & 22.4 & 241 & 13.6 & 21.5 & 497 & 13.6 \\
TAG & 22.0 & 328 & 13.2 & 20.0 & 516 & 13.3 \\
Neuroglian & 20.3 & 448 & 9.4 & 24.3 & 255 & 9.5 \\
\hline
\end{tabular}

The $z$ score has been calculated according to Lipman and Pearson (1985).

The intracellular domain of the HB3 protein is disrupted in $\mathrm{rst}^{\mathrm{CT}}$ mutants

The genetic comapping of irreC and rst mutations, their complex complementation pattern and the HB3 expression pattern during retinal development (see above) prompted us to examine the integrity of the HB3 transcript in $r s t^{C T}$ mutants. This was done by using PCR to amplify rst genomic DNA corresponding to the wildtype HB3 cDNA. A fragment generated by the amplification of the genomic region between nucleotides 1834 and 2351 (coding for amino acids 544-715 in the potential transmembrane and intracellular region of the wildtype $\mathrm{HB} 3$ protein) turned out to be $\sim 100$ bp shorter when $r t^{C T}$ genomic DNA was used. Subsequent sequencing of this fragment revealed a 98-bp deletion (from 1976 to 2073) accompanied by a transition from $C$ to $T$ at posi- tion 1972. The deletion and the resulting frameshift led to a shortened putative protein (652 amino acids), the last 63 amino acids of which differ from the wild-type sequence (i.e., the mutant protein misses the last 175 amino acids of the wild-type form) (Fig. 8). Eighty four percent of the wild- type cytoplasmic domain is eliminated in $r s t^{C T}$. It is concluded that the integrity of the intracellular domain is required for normal cell death in the eye imaginal disc.

\section{Discussion}

The irre $C$ and rst genetic functions, affecting axonal projections (Boschert et al. 1990) and cell death (Wolff and Ready 1991), map in the same chromosomal region, 3C5, and complementation tests performed previously between both loci suggested that irre $C$ and rst might de-

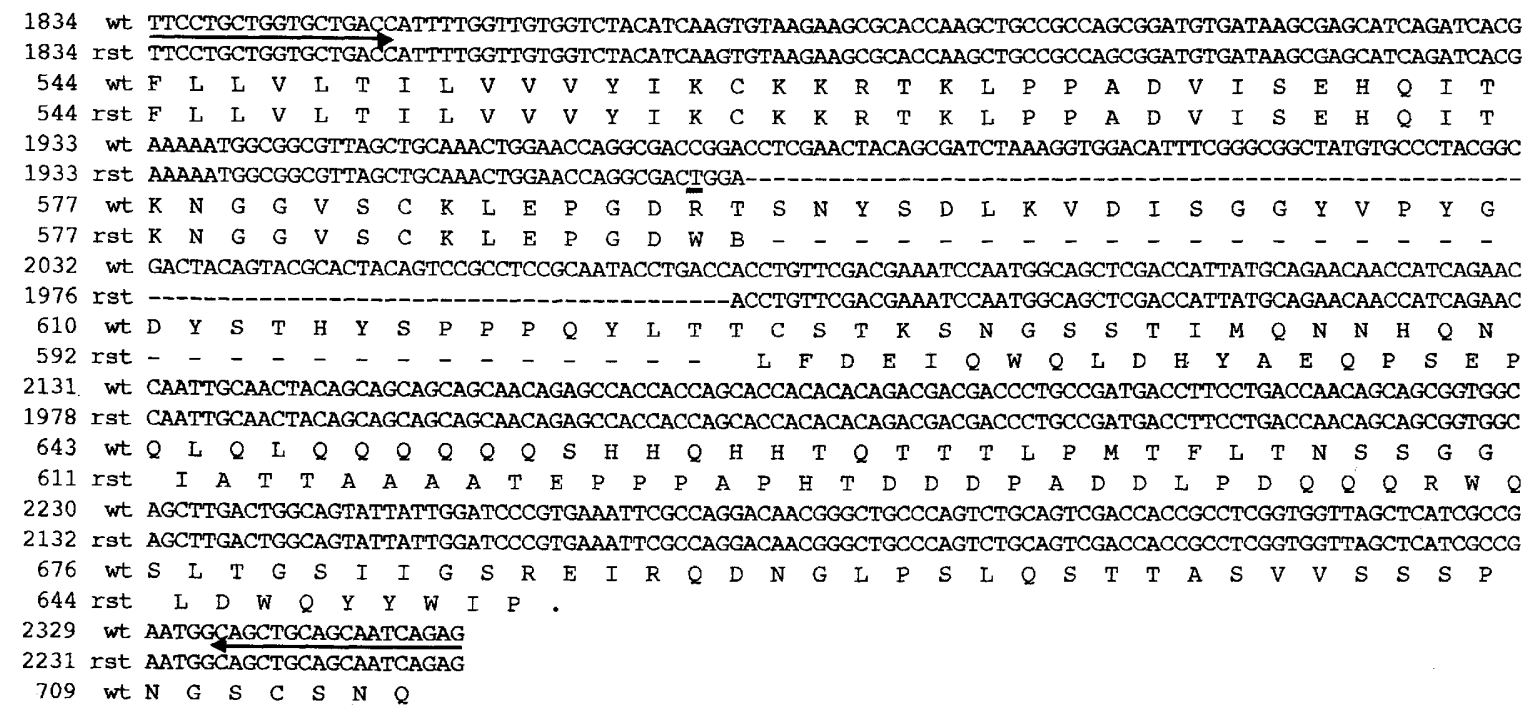

Figure 8. Sequence of the molecular lesion in the genomic irreC-rst region of $r s t^{C T}$ flies. Primers taken from the eighth exon of the HB3-cDNA lead to a shortened PCR product when rst genomic DNA is amplified. The exact location of the primers is indicated by the arrows. The sequence of the wild-type PCR product is identical to the sequence of the respective section of the HB3-cDNA (nucleotides 1834-2351). In the PCR product derived from rst genomic DNA, a 98-bp deletion (from 1976 to 2073 ) was revealed that is accompanied by a transition from $\mathrm{C}$ to $\mathrm{T}$ at position 1972 (underlined). The deletion leads to a frameshift and an according alteration and premature termination of the amino acid sequence of the predicted HB3-protein in rst ${ }^{C T}$ mutants. 
scribe different functional aspects of the same genetic unit (Boschert et al. 1990). It was also shown that the gene had to be expressed in the eye imaginal disc and in two cell populations of the optic lobe. The molecular data presented here support these views. We have cloned $\sim 60 \mathrm{~kb}$ of DNA from 3C5 and identified a transcription unit, spanning $\geqslant 23 \mathrm{~kb}$ of genomic DNA (Fig. 2), which gives rise to an $\sim 5-\mathrm{kb}$-long mRNA present in the embryo, eye imaginal disc, in the developing lamina, and medulla (Fig. 4 and 5). The $P$ element associated with irre $C^{U B 883}$ is inserted at the $5^{\prime}$ end of this transcription unit, providing a likely explanation for the severe reduction in its transcription level seen in the embryo and in the optic lobe. However, a less severe reduction in the level of transcription is observed in the eye imaginal disc (Figs. 4E and 5C), in agreement with the weakness of the eye phenotype of homozygous or hemizygous irre $C^{U B 883}$ mutants. The noncoding $5^{\prime}$ leader sequence of the transcript is interrupted by the proximal inversion breakpoint of In(1)irre $C^{1 R 34}$. In this mutant, a noticeable eye roughness is present, in addition to the optic chiasm defect, and no transcripts could be observed in digoxigenin in situ hybridizations at any developmental stage. The largest cDNA (HB3) derived from the locus encodes a putative transmembrane glycoprotein with similarity to members of the immunoglobulin superfamily. Its intracellular domain is disrupted by the $r s t^{C T}$ mutation, whereas mRNA expression in $r s t^{C T}$ eye imaginal discs is high (Fig. 5D). On the basis of all the above characteristics, we conclude that we have cloned the irreC-rst locus of $D$. melanogaster.

\section{The irreC-rst protein defines a new class of immunoglobulin-like proteins}

The overall organization of the extracellular portion of the irreC-rst protein, which includes five immunoglobulin-like domains and no fibronectin type-III domains, has thus far no counterpart in Drosophila. On the basis of the extent and quality of the similarity, it is more related to the vertebrate proteins DM-GRASP/SC1/ BEN, MAG, and MUC than to fasciclin II, the only other Drosophila protein with five extracellular immunoglobulin-like domains identified so far. The vertebrate molecules, however, also do not align well over the complete length of the extracellular domain (Table 1), and, as shown in Figure 7D, each of the irreC-rst immunoglobulin-like domains shows best similarity to a domain from a different vertebrate protein. The first two immunoglobulin-like domains show characteristics of both $\mathrm{C} 2$ - and V-type domains, making their precise assignment to one of these subsets difficult. The first domain of human DCC that aligns best with domain 1 has been classified as a C2 domain (Fearon et al. 1990), and the second domain of DM-GRASP that aligns best with domain 2 has been classified as a V-type domain (Burns et al. 1991). Furthermore, the contiguity of the immunoglobulin repeats is interrupted between the second and the third domains by a small spacer of 18 amino acids, 10 of which are glycine residues. This spacer is absent in all other immunoglobulin-like proteins showing similarity to the irreC-rst protein, and its removal significantly improves the length of most alignments (Table 1). On the basis of these characteristics, we propose that the irreC-rst protein defines a novel class of immunoglobulin-like molecules. It will be of interest to determine whether there are other molecules in Drosophila sharing this same general structural organization, or whether the features shown by the irreC-rst protein are unique.

The similarity between the irreC-rst protein and the known isoform of DM-GRASP does not extend to the intracellular region. No extensive similarity between the sequence of the putative intracellular portion of the irreC-rst protein and any other sequence present in the data bases could be found. However, it does contain a glutamine-rich opa-like segment (amino acids 637-658) with highest similarity to that found in the Drosophila gene small optic lobes (Delaney et al. 1991). opa sequences, integral parts of many developmentally active proteins, were first identified in the Notch gene of Drosophila (Wharton et al. 1985) and later in mouse (Danielsen et al. 1986). In humans, expansion of CAG repeats coding for polyglutamine tracts have been found to underlie Kennedy's and Huntington's disease (La Spada et al. 1991; Huntington's Disease Collaborative Research Group 1993). At present, the function of glutamine tracts in proteins is unknown.

Another striking characteristic of the intracellular domain of the irreC-rst protein is its high content of serine and threonine, which accounts for $28.1 \%$ of the amino acid composition of that part of the protein as opposed to only $13.9 \%$ in the rest of the molecule. Protein phosphorylation at serine, threonine, and tyrosine residues has long been recognized as crucial to a number of intracellular signaling pathways, and circumstantial evidence (discussed below) suggests that irreC-rst could be involved directly in signal transduction. Screening of the PROSITE data base (Bairoch 1992) has identified three potential phosphorylation sites, one for PKA ( $\mathrm{T}$ at position 562) and two for PKC (S at 582 and 626). Tyrosine605 could, in principle, also qualify as a putative phosphorylation site as it is preceded by a lysine at position 598 and an aspartate at position 600.

Another potentially significant finding is the presence in the irreC-rst protein of the carboxy-terminal pattern IYxxxYxRxxxxxx[LM]LPxxxxx, characteristic of liganddependent tyrosine kinases. This pattern is contained in their putative site of autophosphorylation, which is highly conserved among the family of insulin receptorlike tyrosine kinases (Yarden and Ullrich 1988), the c-ros and sevenless receptor tyrosine kinases (Matsushime et al. 1986; Hafen et al. 1987), and the trk family of highaffinity receptors for nerve growth factor and related neurotrophic factors (BDNF and NT-3; Park 1991; Ragsdale and Woodgett 1991). The irreC-rst protein is most likely not a kinase itself, but the sharing of the above pattern with the autophosphorylation site of protein kinases hints at the possibility that there might be some interaction taking place (e.g., tyrosine- 749 could be a site for phosphorylation). 
The irreC-rst protein plays a role in programmed cell death

The absence of the last 175 amino acids of the cytoplasmic domain of the irreC-rst protein in $r s t^{C T}$ mutants is highly suggestive of the involvement of the molecule in signal transduction, at least in the eye imaginal disc. According to Wolff and Ready (1991) rst ${ }^{C T}$ mutants show reduced cell death of more than one cell population during eye development: First, there is a normal round of cell death just in front of the morphogenetic furrow that is absent in $r s t^{C T}$ (Fig. 11 of Wolff and Ready 1991). Second, between 35 and $50 \mathrm{hr}$ of pupal development (i.e., well after the assembly of the ommatidial clusters), two to three surplus cells per ommatidium are removed in the wild type, but not in the mutant. This timing is consistent with the view that cell death is the fate of those cells in the eye imaginal disc that have failed to participate in ommatidium formation (Wolff and Ready 1991). The spatial and temporal regulation of expression of irreC-rst mRNA correlates well with both rounds of cell death. Expression is strong just in front of the morphogenetic furrow (Fig. 4C), and the gene is expressed transiently between 35 and $50 \mathrm{hr}$ of pupal development in cells in between the ommatidial cell clusters (Fig. 5B). Surplus cells are normally eliminated from that cell population. It is suggested by the data in Figure 5D that the surviving surplus cells in $r s t^{C T}$ mutants express the irre C-rst mRNA, but obviously, the encoded mutant protein is not sufficient to induce cell death. At $65 \mathrm{hr}$ of pupal development, at the time of the degeneration of marginal ommatidia, irreC-rst mRNA expression is already down-regulated. It fits well that degeneration of marginal ommatidia takes place on schedule in $r s t^{C T}$ mutants (Wolff and Ready 1991). These data suggest that the irre C-rst locus is not a universal part of the program of cell death (Ellis and Horvitz 1986; Oppenheim et al. 1990; Tomei and Cope 1991; Raff 1992); rather, it is involved in the triggering of that program under specific developmental conditions. The wild-type irreC-rst protein could, for instance, function as a receptor for positional information that directly triggers the suicide program. Alternatively, if the default fate of a cell in the eye imaginal disc is death, as suggested by Bonini et al. (1993) and evidenced from other systems (Barres et al. 1992; Raff 1992), then the irreC-rst product could transduce a signal leading to the inhibition of a differentiation pathway, thus removing the cell's inhibition to commit suicide. In any case, the molecular lesion found in the $r s t^{C T}$ mutation implies that the intracellular domain of the wild-type irreC-rst protein must play a crucial role in this process. However, understanding the exact way in which it performs its function as well as the relevant importance of the several intracellular subdomains clearly requires further work.

\section{How does the irreC-rst protein affect axonal pathfinding?}

irreC-rst is the first genetic locus coding for a member of the immunoglobulin superfamily that has been cloned starting from a mutant axonal projection defect. Neural cell adhesion molecules belonging to this superfamily have long been associated with neurite outgrowth and axonal pathfinding (Edelman 1986; Doherty and Walsh 1992). It is therefore possible that the axonal projection defects of irre $C$ mutants will find their straightforward explanation in axonal pathfinding problems arising from the absence of a neural cell adhesion molecule. It has been shown by Boschert et al. (1990) that the projection defects in the first optic chiasm correlate with the displacement of optic lobe pioneer neurons. Accordingly, genetic mosaics showed that retinal fibers were misguided rather than unable to navigate. Because the optic lobe pioneer neurons are born in the embryo (Tix et al. 1989), it seems that the embryonic expression of the irreC-rst gene could affect postembryonic formation of the first optic chiasm. On the other hand, there is strong expression of the irreC-rst gene in the larval and pupal optic lobe as well, especially in the lamina and in the medulla cortex (Figs. 4D and 5A). The postembryonic medullar expression could be the basis for the epigenetically independent defects of the second optic chiasms in irreC mutants.

Interestingly, the rst ${ }^{C T}$ deletion has no effect on the neural phenotype, that is, the integrity of the intracellular domain of the peptide encoded by the HB3 cDNA is not necessary for normal formation of optic chiasms. This could be explained by postulating the existence of additional secreted or glycosyl-phosphatidylinositol (GPI)-anchored isoforms (Ferguson and Williams 1988) of the irreC-rst protein that interfere with or are involved in cell adhesion. The availability of molecular probes, such as antibodies directed to different portions of the protein, and characterization of additional irreC-rst cDNAs will allow this hypothesis to be tested directly.

\section{Materials and methods}

Fly stocks

Isolation, genotypic characteristics, and conditions of maintenance of all fly stocks used in this study have been described previously (Boschert et al. 1990).

\section{Basic recombinant DNA techniques}

Phage and plasmid DNA purification, restriction enzyme digestions, agarose electrophoresis, and subcloning were done by standard methods (Maniatis et al. 1982; Sambrook et al. 1989).

\section{Southern and Northern blots}

For genomic Southern blot analysis, DNA prepared from adult flies according to Gray et al. (1991) was fractionated on $0.7 \%$ agarose gels and blotted onto Biodyne membranes (Pall Corp.) according to the manufacturer's instructions. Hybridization was performed using $\left[{ }^{32} \mathrm{P}\right] \mathrm{dCTP}$-labeled probes $\left(\mathrm{sp}\right.$. act. $10^{7}-10^{8}$ $\mathrm{dpm} / \mu \mathrm{g}$ ) as described in Bender et al. (1983).

For Northern blot analysis, RNA was extracted from embryonic, larval, pupal, or adult flies using the hot phenol method (Jowett 1986). Poly(A) ${ }^{+}$RNA $(10 \mu g)$, enriched by oligo(dT)- 
cellulose chromatography (Sambrook et al. 1989), was size fractionated on formaldehyde-agarose gels and blotted onto nitrocellulose (BAS85, Schleicher \& Schuell). Hybridization was performed at $42^{\circ} \mathrm{C}$ in $50 \%$ formamide, $5 \times$ SSPE, $5 \times$ Denhardt's solution, $0.1 \%$ SDS, and $0.1 \mathrm{mg} / \mathrm{ml}$ of salmon sperm DNA with probes that were ${ }^{32} \mathrm{P}$-labeled by random priming (Feinberg and Vogelstein 1983). The blots were washed three times in $0.2 \times$ SSPE, $0.2 \%$ SDS, at $42^{\circ} \mathrm{C}$. After autoradiographic detection of hybridizing transcripts, the blots were washed again under more stringent conditions $\left(50^{\circ} \mathrm{C}, 0.2 \times \mathrm{SSPE}, 0.2 \%\right.$ SDS). The BRL RNA ladder was used as size marker.

\section{Library Construction}

DNA of adult flies from the stock irre $C^{U B 883-F 13 C}$, prepared as described above, was digested partially with $\mathrm{MboI}$ as described in Maniatis et al. (1982) and size fractionated in $0.6 \%$ low melting agarose (BRL). The region containing fragments in the range $12-18 \mathrm{~kb}$ was excised from the gel, and the DNA was purified from agarose by first heating at $65^{\circ} \mathrm{C}$ followed by the addition of $2 \mathrm{vol}$ of $\mathrm{H}_{2} \mathrm{O}$, and two rounds of phenol-chloroform extraction and ethanol precipitation. Size-fractionated fragments $(0.5 \mu \mathrm{g})$ were ligated to completely BamHI-XhoI-digested $\lambda$ Dash DNA (Stratagene cloning systems), in three separate reactions, using vector-to-insert molar ratios of $1: 2,1: 1$, and 2:1, respectively. Reactions were packaged in vitro using Amersham's packaging extract kit. Together, the three packaged reactions yielded $\sim 4 \times 10^{5}$ independent recombinants after selection in Escherichia coli $\mathrm{P} 2392$ and were screened without further amplification using the P-element insert of clone p $\pi$ p25.7wc (Karess and Rubin 1984).

\section{Chromosomal walk}

Screening of genomic libraries was done predominantly with random primer-directed, biotinylated probes, whereas ${ }^{32} \mathrm{P}$-oligolabeled probes were used for cDNA library screens. Labeling conditions were as described in Feinberg and Vogelstein (1983), with either $50 \mu \mathrm{Ci}$ of $\left[{ }^{32} \mathrm{P}\right] \mathrm{dCTP}$ or $3 \mathrm{~mm}$ Bio-16 dATP (Boehringer). Libraries were usually plated at $10^{4} \mathrm{pfu} / \mathrm{plate}$, transferred to nitrocellulose filters, and hybridized as described in Bender et al. (1983). Washes were done either three times in $0.1 \times \mathrm{SSPE}+0.1 \% \mathrm{SDS}$, for $20 \mathrm{~min}$ at $50^{\circ} \mathrm{C}\left({ }^{32} \mathrm{P}\right.$-labeled probes $)$, or sequentially in $2 \times$ SSC $+0.1 \%$ SDS, $0.2 \times$ SSC $+0.1 \%$ SDS at room temperature and, finally, twice in $0.16 \times \mathrm{SSC}+0.1 \%$ SDS, for $15 \mathrm{~min}$ at $50^{\circ} \mathrm{C}$ (biotinylated probes). Positive signals were detected by autoradiography $\left({ }^{32} \mathrm{P}\right.$-labeled probes) or developed using the "Bluegene" kit protocol (BRL) with minor modifications.

\section{In situ hybridization to polytene chromosomes}

Biotinylated DNA probes labeled as described above were hybridized to polytene chromosome squashes as described in Boschert et al. (1990).

\section{In situ hybridization to whole mounts}

Localization of irreC-rst mRNAs in whole-mount preparations of embryos and larval and pupal brains was done as described by Tautz and Pfeifle (1989), with minor modifications. Probes consisted of isolated cDNA fragments that were labeled with digoxigenin-dUTP (Boehringer Mannheim) according to the manu- facturer's instructions, except that the final concentration of hexanucleotide primers in the labeling mixture was increased to $2 \mathrm{mg} / \mathrm{ml}$.

\section{DNA sequencing and analysis}

For sequencing, cDNA HB3 was restricted initially with EcoRI and subcloned in Bluescript KS + (Stratagene). Deletions were then generated by digestion at suitable restriction sites in the insert and in the polylinker followed by religation. Sequence was determined by the dideoxynucleotide termination method (Sanger et al. 1977) from double-stranded plasmid templates using an EMBL automatic sequencer (Ansorge et al. 1986). Sequencing reactions were carried out as described by Igloi and Schiefermayr (1993). Gaps were filled and areas of ambiguity resolved by using walking primers. Primers were also used to completely sequence the genomic DNA corresponding to cDNA HB3 and to determine the exact location of exon-intron borders.

DNA sequences were assembled and translated using the MacMolly sequence analysis program package. Signal peptide prediction was done using the program PLOTA SIG., which uses the algorithm developed by Van Heijne et al. (1986). Similarity searches were performed on the GenBank, EMBL, and PIR data bases using the FASTA (Pearson and Lipman 1988) and BLAST programs (Altschul et al. 1990). Codon usage was checked using the GCG program CodonFrequency produced by J.M. Cherry based on 412 genes found in GenBank release 63.

\section{PCR techniques}

PCR was carried out using Taq DNA polymerase (U.S. Biochemical) in the presence of $\sim 0.5 \mu \mathrm{g}$ of genomic DNA $10 \mathrm{mM}$ Tris- $\mathrm{HCl}$ (pH 8.5), $50 \mathrm{mM} \mathrm{KCl} 1.5 \mathrm{~mm} \mathrm{MgCl}_{2}$, and $0.001 \%$ gelatin together with $0.2 \mathrm{mM} \mathrm{dNTP}$, and $1 \mu \mathrm{g}$ of each primer. After an initial denaturation step for $2 \mathrm{~min}, 30$ cycles at $93^{\circ} \mathrm{C}$ ( $1 \mathrm{~min}$ ), $55^{\circ} \mathrm{C}(1 \mathrm{~min})$, and $72^{\circ} \mathrm{C}(2 \mathrm{~min})$ and a final elongation at $72^{\circ} \mathrm{C}$ for $7 \mathrm{~min}$ followed. Ten percent of the product was used for electrophoretic analysis, and the rest was freed of excess primers and dNTPs using SpinBind units (FMC) according to the manufacturer's instructions. One-half of the resulting DNA was subjected to cycle sequencing (Cycle Sequencing Kit, U.S. Biochemical) with $20 \mathrm{ng}$ of the fluorescently labeled PCR primer as sequencing primer (Igloi and Schiefermayr 1993).

\section{Acknowledgments}

We thank B. Hovemann, E. Buchner, and A. Preiss for the generous gift of genomic and cDNA libraries; B. Bausenwein, T. Schimansky, S. Tix, M. Heisenberg, A. Preiss, R. Cassada, E. Hafen, and S. Schneuwly for critically reading the manuscript; and T. Wolff and D. Ready for helpful discussions. Special thanks go to Andreas Kottmann, who drew our attention to some features of the protein sequence. R. Gafert, S. Peterreins, S. Krause, and E. Schiefermayr supplied skillful technical support, F. Barleben helped with the sequence analysis, and U. Boschert prepared the silver impregnated brain sections. During the initial stages of this project, R.G.P.R. was recipient of a Postdoctoral Fellowship from the Brazilian Conselho Nacional de Desenvolvimento Científico e Tecnológico (CNPq). Our work was supported by the DFG-Schwerpunktprogramm Dynamik und Stabilisierung neuronaler Strukturen (grants Fi 336/ 4) and by the Fond der Chemischen Industrie. 
The publication costs of this article were defrayed in part by payment of page charges. This article must therefore be hereby marked "advertisement" in accordance with 18 USC section 1734 solely to indicate this fact.

\section{Note}

The sequence reported in this paper has been submitted to the GenBank data library under accession number L11040.

\section{References}

Ansorge, W., B.S. Sproat, J. Stegemann, and C. Schwager. 1986. A non-radioactive automated method for DNA sequence determination. J. Biochem. Biophys. Methods 13: 315-323.

Altschul, S.F., W. Gish, W. Miller, E.W. Myers, and D.J. Lipman. 1990. Basic local alignment search tool. $J$. Mol. Biol. 215: 403-410.

Bairoch, A. 1992. Prosite: A dictionary of sites and patterns in proteins. Nucleic Acids Res. 20: 2013-2018.

Barres, B.A., I.K. Hart, H.S.R.Coles, J.F. Burne, J.T. Voyvodic, W.D. Richardson, and M.C. Raff. 1992. Cell death and control of cell survival in the oligo-dendrocyte lineage. Cell 70: $31-46$.

Barthels, D., M.-J. Santoni, W. Wille, C. Ruppert, J.-C. Chaix, M.-R. Hirsh, J.C. Fontecilla-Camps, and C. Goridis. 1987. Isolation and nucleotide sequence of mouse NCAM cDNA that codes for a $M_{r} 79,000$ polypeptide without a membrane spanning region. EMBO J. 6: 907-914.

Bender, W., P. Spierer, and D. Hogness. 1983. Chromosomal walking and jumping to isolate from the DNA the ace and rosy loci and the Bithorax complex in Drosophila melanogaster. J. Mol. Biol. 168: 17-33.

Bieber, A.J., P.M. Snow, M. Hortsch, N.H. Patel, J.R. Jacobs, Z.R. Traquina, J. Schilling, and C.S. Goodman. 1989. Drosophila neuroglian: A member of the immunoglobulin superfamily with extensive homology to the vertebrate neural adhesion molecule L1. Cell 59: 447-460.

Bixby, J.L. and W.A. Harris. 1991. Molecular mechanisms of axon growth and guidance. Annu. Rev. Cell. Biol. 7: 117159.

Bonini, N.M., W.M. Leiserson, and S. Benzer. 1993. The eyes absent gene: Genetic control of cell survival and differentiation in the developing Drosophila eye. Cell 72: 1-20.

Boschert, U. 1991. "Charakterisierung von Mutanten mit irregulären optischen Chiasmata von Drosophila melanogaster," Ph.D. thesis. University of Freiburg, Freiburg, Germany.

Boschert, U., R.G.P. Ramos, S. Tix, G. Technau, and K.-F. Fischbach, 1990. Genetic and developmental analysis of irreC, a function required for optic chiasm formation in Drosophila. I. Neurogenet. 6: 153-171.

Burns, F.R., S. Von Kannen, L. Guy, J.A. Raper, J. Kamholz, and S. Chang, 1991. DM-GRASP, a novel immunoglobulin superfamily axonal surface protein that supports neurite extension. Neuron 7: 209-220.

Cavener, D. 1987. Comparison of the consensus sequence flanking translational start sites in Drosophila and vertebrates. Nucleic Acids Res. 15: 1353-1361.

Cunningham, B.A, J.J. Hemperley, B.A. Murray, E.A. Prediger, R. Brackenbury, and G.M. Edelman. 1987. Neural cell adhesion molecule: Structure, Ig-like domains, cell surface modulation and alternative RNA splicing. Science 236: 799-806.

Danielsen, M., J.P. Northrop, and G.M. Ringold. 1986. The mouse glucocorticoid receptor: Mapping of functional domains by cloning, sequencing and expression of wild-type and mutant receptor proteins. EMBO J. 5: 2513-2522.
Delaney, S.J., D.C. Hayward, F. Barleben, K.-F. Fischbach, and G.L. Miklos. 1991. Molecular cloning and analysis of small optic lobes, a structural brain gene of Drosophila melanogaster. Proc. Natl. Acad. Sci. 88: 7214-7218.

Dodd, J. and T.M. Jessel. 1988. Axon guidance and patterning of neuronal projections in vertebrates. Science 242: 692-699.

Doherty, P. and F.S. Walsh. 1992. Cell adhesion molecules, second messengers and axonal growth. Curr. Opin. Neurobiol. 2: 595-601

Edelman, G.M. 1986. Cell adhesion molecules in the regulation of animal form and tissue pattern. Annu. Rev. Cell Biol. 2: $81-116$.

Elkins, T., M. Hortsch, A.J. Bieber, P.M. Snow, and C.S. Goodman. 1990. Genetic analysis of a Drosophila neural cell adhesion molecule: Interaction of fasciclin I and Abelson tyrosine kinase mutations. Cell 60: $565-575$.

Ellis, H.M. and H.R. Horvitz. 1986. Genetic control of programmed cell death in the nematode $C$. elegans. Cell 44: 817-829.

Fearon, E.R., K.R. Cho, J.M. Nigro, S.E. Kern, J.W. Simons, J.M. Ruppert, S.R. Hamilton, A.C. Preisinger, G. Thomas, K.W. Kinzler, and B. Vogelstein. 1990. Identification of a chromosome $18 \mathrm{q}$ gene that is altered in colorectal cancers. Science 247: 49-56.

Feinberg, A.P. and B. Vogelstein. 1983. A technique for radiolabelling DNA restriction fragments to high specific activity. Anal. Biochem. 132: 6-13.

Ferguson, M.A.J. and A.F. Williams. 1988. Cell-surface anchoring of proteins via glycosyl-phosphatidylinositol structures. Annu. Rev. Biochem. 57: 285-320

Fessler, L.I., A.G. Campbell, K.G. Duncan, and J.H. Fessler. 1987. Drosophila Laminin: Characterization and localization. J. Cell Biol. 105: 2383-2391.

Fickett, J.W. 1982. Recognition of protein coding regions in DNA sequences. Nucleic Acids. Res. 10: 5303-5318.

Fischbach, K.-F. and G. Technau. 1984. Cell degeneration in the developing optic lobes of the sine oculis and small optic lobes mutants of Drosophila melanogaster. Dev. Biol. 104: 219-239.

Furley, A.J., S.B. Morton, D. Manalo, D. Karagogeos, J. Dodd, and T.M. Jessell. 1990. The axonal glycoprotein TAG-1 is an immunoglobulin superfamily member with neurite outgrowth-promoting activity. Cell 61: 157-170.

Gennarini, G., G. Cibelli, G. Rougon, M.-G. Mattei, and C. Goridis. 1989. The mouse neuronal cell surface protein F3: A phosphatidylinositol-anchored member of the immunoglobulin superfamily related to chicken contactin. I. Cell Biol. 109: 775-788.

Gray, M., A. Charpentier, K. Walsh, P. Wu, and W. Bender. 1991. Mapping point mutations in the Drosophila rosy locus using denaturing gradient gel blots. Genetics 127: 139-149.

Grenningloh, G. and C.S. Goodman. 1992. Pathway recognition by neuronal growth cones: Genetic analysis of neural cell adhesion molecules in Drosophila. Curr. Opin. Neurobiol. 2: $42-47$.

Grenningloh, G., A.J. Bieber, E.J. Rehm, P.M. Snow, Z.R. Traquina, M. Hortsch, N.H. Patel, and C.S. Goodman. 1990. Molecular genetics of neuronal recognition in Drosophila: Evolution and function of immunoglobulin superfamily cell adhesion molecules. Cold Spring Harbor Symp. Quant. Biol. 55: $327-340$.

Grenningloh, G., E.J. Rehm, and C.S. Goodman. 1991. Genetic analysis of growth cone guidance in Drosophila: Fasciclin II functions as a neuronal recognition molecule. Cell 67: 4557.

Hafen, E., K. Basler, J.E. Edstroem, and G.M. Rubin. 1987. sev- 
enless, a cell-specific homeotic gene of Drosophila, encodes a putative transmembrane receptor. Science 236: 55-63.

Harrelson, A.L. and C.S. Goodman. 1988. Growth cone guidance in insects: Fasciclin II is a member of the immunoglobulin superfamily. Science 242: 700-708.

Hengartner, M.O., R.E. Ellis, and H.R. Horvitz. 1992. Caenorhabditis elegans gene ced-9 protects cells from programmed cell death. Nature 356: 494-499.

Hollyday, M. and V. Hamburger. 1976. Reduction of the naturally occurring motor neuron loss by enlargement of the periphery. J. Comp. Neurol. 170: 311-320.

Hortsch, M. and C.S. Goodman. 1991. Cell and substrate adhesion molecules in Drosophila. Annu. Rev. Cell Biol. 7: 505557.

Huntington's Disease Collaborative Research Group. 1993. A novel gene containing a trinucleotide repeat that is expanded and unstable on Huntington's disease chromosomes. Cell 72: $971-973$.

Hynes, R.O. and A.D. Lander. 1992. Contact and adhesive specificities in the associations, migrations and targeting of cells and axons. Cell 68: 303-322.

Igloi, G.L. and E. Schiefermayr. 1993. Enzymatic addition of fluorescein- or biotin-riboUTP to oligonucleotides results in primers suitable for DNA sequencing and PCR. BioTechniques 15: 486-497.

Jessel, T.M. 1988. Adhesion molecules and the hierarchy of neural development. Neuron 1: 3-13.

Jowett, T. 1986. Preparation of nucleic acids. In Drosophila. $A$ practical approach (ed. D.B. Roberts), pp. 275-286. IRL Press, Oxford, UK.

Karess, R. and G.M Rubin. 1984. Analysis of P-transposable element functions in Drosophila. Cell 38: 135-146.

Katz, M.J. and R.J. Lasek. 1978. Evolution of the nervous system. Role of ontogenetic mechanisms in the evolution of matching populations. Proc. Natl. Acad. Sci. 75: 1349-1352.

Kyte, J. and R.F. Doolittle. 1982. A simple method for displaying the hydropathic character of a protein. J. Mol. Biol. 157: 105132.

La Spada, A.R., E.M. Wilson, D.B. Lubahn, A.E. Harding, and K.H. Fischbeck. 1991. Androgen receptor gene mutations in $\mathrm{X}$-linked spinal and bulbar muscular atrophy. Nature 352: 77-79.

Lefèvre, G. and M.M. Green. 1972. Genetic duplication in the white-split interval of the $\mathrm{X}$ chromosome in Drosophila melanogaster. Chromosoma 36: 391-412.

Lehmann, J.M., G. Riethmüller, and J.P. Johnson. 1989. MUC18, a marker of tumor progression in human melanoma, shows sequence similarity to the neural cell adhesion molecules of the immunoglobulin superfamily. Proc. Natl. Acad. Sci. 86: 9891-9895

Lipman, D.J. and W.R. Pearson. 1985. Rapid and sensitive protein similarity searches. Science 227: 1435-1441.

Maniatis, T., E.F. Fritsch, and J. Sambrook. 1982. Molecular cloning: A laboratory manual. Cold Spring Harbor Laboratory, Cold Spring Harbor, New York.

Matsushime, H., L.-H. Wang, and M. Shibuya. 1986. Human c-ros-1 gene homologous to the v-ros sequence of UR2 sarcoma virus encodes for a transmembrane receptor-like molecules. Mol. Cell. Biol. 6: 3000-3004.

Mendelsohn, C.L., E. Wimmer, and V. Racaniello. 1989. Cellular receptor for poliovirus: Molecular cloning, nucleotide sequence, and expression of a new member of the immunoglobulin superfamily. Cell 56: 855-865.

Mozer, B., R. Marlor, S. Parkhurst, and V. Corces. 1985. Characterization and developmental expression of a Drosophila ras oncogene. Mol. Cell. Biol. 5: 885-889.
Oppenheim, R.W., D. Prevette, M. Tytell, and S. Homma. 1990. Naturally occurring and induced neuronal cell death in the chick embryo in vivo requires protein and RNA synthesis: Evidence for the role of cell death genes. Dev. Biol. 138: 104-113.

Park, M. 1991. Lonesome receptors find their mates. Curr. Biol. 1: 248-250.

Patel, N.H., P.M. Snow, and C.S. Goodman. 1987. Characterization and cloning of fasciclin III: A glycoprotein expressed on a subset of neurons and axon pathways in Drosophila. Cell 48: 975-988.

Pearson, W.R. and D.J. Lipman. 1988. Improved tools for biological sequence comparison. Proc. Natl. Acad. Sci. 85: 2444-2448.

Pirrota, V., C. Hatfield, and G.H.J. Pretorius. 1983. Microdissection and cloning of the white locus and the $3 \mathrm{~B} 1-3 \mathrm{C} 2$ region of Drosophila X chromosome. EMBO I. 6: 927-934.

Pourquié, O., C. Corbel, J.-P. Le Caer, J. Rossier, and N.M. Le Douarin. 1992a. BEN, a surface glycoprotein of the immunoglobulin superfamily, is expressed in a variety of developing systems. Proc. Natl. Acad. Sci. 89: 5261-5265.

Pourquié, O., M.E.R. Hallonet, and N.M. Le Douarin. 1992b. Association of BEN glycoprotein expression with climbing fiber axonogenesis in the avian cerebellum. I. Neurosci. 12: 1548-1557.

Raff, M.C. 1992. Social controls on survival and cell death. Nature 356: 397-400.

Ragsdale, C. and J. Woodgett. 1991. trking neurotrophic receptors. Nature 350: 660-661.

Rathjen, F.G. and T.M. Jessell. 1991. Glycoproteins that regulate the growth and guidance of vertebrate axons: Domains and dynamics of the immunoglobulin/fibronectin type III subfamily. Semin. Neurosci. 3: 297-307.

Rathjen, F.G., J.M. Wolff, R. Frank, F. Bonhoeffer, and U. Rutishauser. 1987. Membrane glycoproteins involved in neurite fasciculation. J. Cell Biol. 104: 343-353.

Reichardt, L.F. and K.J. Tomaselli. 1991. Extracellular matrix molecules and their receptors: Functions in neural development. Annu. Rev. Neurosci. 14: 531-570.

Salzer, J.L., W.P. Holmes, and D.R. Colman. 1987. The amino acid sequences of the myelin-associated glycoproteins: Homology to the Ig-superfamily. J. Cell.Biol. 104: 957-965.

Sambrook, J., E.F. Fritsch, and T. Maniatis. 1989. Molecular cloning: A laboratory manual, 2nd. ed. Cold Spring Harbor Laboratory Press, Cold Spring Harbor, New York.

Sanger, F., S. Nicklen, and A.R. Coulson. 1977. DNA sequencing with chain terminating inhibitors. Proc. Natl. Acad. Sci. 74: 5463-5467.

Shaw, G. and R. Kamen. 1986. A conserved AU sequence from the $3^{\prime}$ untranslated region of GM-CSF mRNA mediates selective mRNA degradation. Cell 46: 659-667.

Stamenkovic, I. and B. Seed. 1990. The B-cell antigen CD22 mediates monocyte and erythrocyte adhesion. Nature 345: 74-77.

Takeichi, M. 1991. Cadherins cell adhesion receptors as a morphogenetic regulator. Science 251: 1451-1455.

Tanaka, H., T. Matsui, A. Agata, M. Tomura, I. Kubota, K.C. McFarland, W. Kohr, A. Lee, H.S. Phillips, and D.L. Shelton. 1991. Molecular cloning and expression of a novel adhesion molecule, SCl. Neuron 7: 535-545.

Tautz, D. and C. Pfeifle. 1989. A non-radioactive in situ hybridization method for the localization of specific RNAs in Drosophila embryos reveals translational control of the segmentation gene hunchback. Chromosoma 98: 81-85.

Tix, S., J.S. Minden, and G.M. Technau. 1989. Pre-existing neuronal pathways in the developing optic lobes of Drosophila. Development 105: 739-746. 
Tomei, L.D. and F.O. Cope. 1991. Apoptosis: The molecular basis of cell death. Cold Spring Harbor Laboratory Press, Cold Spring Harbor, New York.

Van Heijne, G. 1986. A new method for predicting signal sequence cleavage sites. Nucleic Acids Res. 14: 4683-4690.

Vaux, D.L., I.L. Weissman, and S.K. Kim. 1992. Prevention of programmed cell death in Caenorhabditis elegans by human bcl-2. Science 258: 1955-1957.

Volkmer, H., B. Hassel, J.M. Wolff, R. Frank, and F.G. Rathjen. 1992. Structure of the axonal surface recognition molecule neurofascin and its relationship to a neural subgroup of the immunoglobulin superfamily. J. Cell Biol. 118: 149-161.

Walsh, F.S. and P. Doherty. 1991. Structure and function of the gene for neural cell adhesion molecule. Sem. Neurosci. 3: 271-284.

Welshons, W.J. and H.J. Welshons. 1986. Enhancement and suppression of a euchromatic position effect at Notch in Drosophila. Genetics 113: 337-354.

Wharton, K.A., B. Yedvobnick, V.G. Finnerty, and S. ArtavanisTsakonas. 1985. Opa: A novel family of transcribed repeats shared by the Notch locus and other developmentally regulated loci in D. melanogaster. Cell 40: 55-62.

Williams, A.F. and A.N. Barclay. 1988. The immunoglobulin superfamily-Domains for cell surface recognition. Annu. Rev. Immunol. 6: 381-405.

Wolff, T. and D.F. Ready. 1991. Cell death in normal and rough eye mutants of Drosophila. Development 113: 825-839.

Yarden, Y. and A. Ullrich. 1988. Growth factor receptor tyrosine kinases. Annu. Rev. Biochem. 57: 443-478.

Zinn, K., L. McAllister, and C.S. Goodman. 1988. Sequence analysis and neuronal expression of fasciclin I in grasshopper and Drosophila. Cell 53: 577-587. 


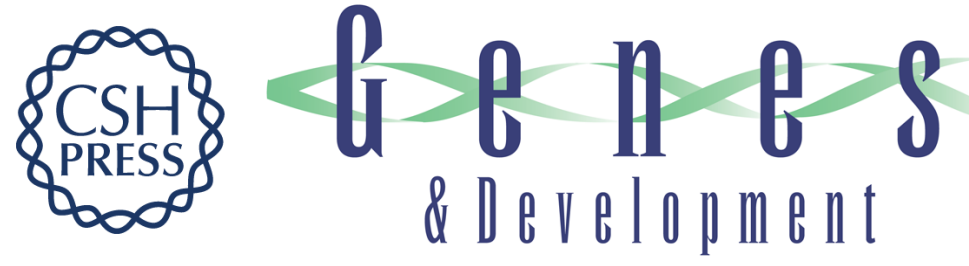

\section{The irregular chiasm C-roughest locus of Drosophila, which affects axonal projections and programmed cell death, encodes a novel immunoglobulin-like protein.}

R G Ramos, G L Igloi, B Lichte, et al.

Genes Dev. 1993, 7:

Access the most recent version at doi:10.1101/gad.7.12b.2533

References This article cites 81 articles, 27 of which can be accessed free at:

http://genesdev.cshlp.org/content/7/12b/2533.full.html\#ref-list-1

License

Email Alerting Service

Receive free email alerts when new articles cite this article - sign up in the box at the top right corner of the article or click here.

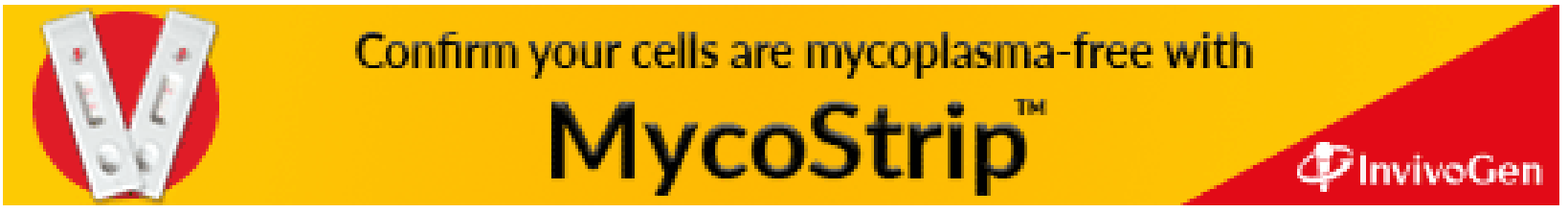

